\title{
A Bayesian Network Analysis of Ethical Behavior
}

ournal of Macromarketing $1-20$

(C) The Author(s) 2015

Reprints and permission:

sagepub.com/journalsPermissions.nav DOI: $10.1|77 / 0276| 467 \mid 5607620$ jmk.sagepub.com

(S)SAGE

\author{
Ahmet Ekici' and Sule Onsel Ekici ${ }^{2}$
}

\begin{abstract}
Using one of the major domains of macromarketing - ethics - this paper aims to introduce the Bayesian network (BN) method and demonstrate its added value for macro-level decision makers. Bayesian networks are particularly important for macromarketers because they allow researchers to analyze a domain from a system perspective. The $\mathrm{BN}$ approach is considered one of the most powerful tools for observing system changes. The method can also deal with multiple variables at once, which can lead to efficient scenario analyses, critical for understanding how a system functions. As such, BNs offer a powerful tool for macromarketers who deal with systems, interactions, and higher levels of aggregation. We believe that the adoption of this methodology by macromarketing researchers is likely to contribute to the discipline by advancing the understanding of how certain systemic/network relationships and various domains of macromarketing work.
\end{abstract}

\section{Keywords}

bayesian network, ethics, macromarketing method, systems, economic development

\section{Introduction}

Macromarketing scholars have long emphasized the importance of systemic/network approaches to business activities: actions cause reactions, which cause further reactions (e.g. Mittelstaedt, Kilbourne, and Mittelstaedt 2006). At the same time, various scholars have pointed out the lack of (and therefore the need for) appropriate tools for macromarketing analysis. Dixon (2002), for example, called attention to certain shortcomings of the existing work in macromarketing and to the need for new methods by stating:

The limited outlook of much current work, and the lack of coherence among the increasingly narrow threads of thought, reinforces an observation made more than a half century ago: "The multitude of facts thus far assembled seem to add up to very little. One must conclude that something has gone wrong with the method of attack - a new and creative analysis is required" (Alderson and Cox 1948, p. 138). (Dixon 2002).

Similarly, after reviewing the knowledge accumulated about the marketing system over the past four decades, Layton and Grossbart (2006) concluded that a great deal has been done studying inputs and outcomes, but relatively little has emerged that looks at the operation of a system. Layton stresses that methods that macromarketers use should allow a system/network level analysis. Around the same time, Fisk (2006) also pointed out the need for developing methods appropriate for (network level) macromarketing analysis.

As evident from these scholars' calls, there is a need for network/system methods in macromarketing. The objective of this paper is to introduce one such method - the Bayesian network $(\mathrm{BN})$ - and demonstrate its added value for macromarketers. This method allows researchers to analyze a domain from a system perspective. In addition, the BN method is considered one of the most powerful tools for observing system changes. The method can also deal with multiple variables at once, which can lead to efficient scenario analyses, critical for understanding how a system functions. We first provide information about the characteristics and mechanics of the BN methodology and then illustrate it using one of the major domains of macromarketing: ethics.

Ethics is used as the context of this paper for a variety of reasons. Macromarketing scholars have long voiced the need for empirical investigations (particularly mezzo- and macro-levels) of ethical behavior. Murphy and Laczniak (1981) made one of the earliest calls for more research into this issue. More than ten years later, Laczniak (1993) once again highlighted the need for "developing empirical traditions" in business/marketing ethics (p. 93). And more recently, in their attempts to identify a global code of ethical conduct (i.e. the "Hyper Norms"), Laczniak and Kennedy (2011) made another call for empirical investigations of ethical behavior (p. 255). A comprehensive

\footnotetext{
'Faculty of Business Administration, Bilkent University, Ankara, Turkey

${ }^{2}$ Faculty of Engineering, Dogus University, Istanbul, Turkey

\section{Corresponding Author:}

Ahmet Ekici, Bilkent University, Faculty of Business Administration, Ankara 06800, Turkey.

Email: ekici@bilkent.edu.tr
} 
review by Nill and Schibrowsky (2007) also suggested "more research to shed further light" on the ethical frameworks and theories developed over the decades (p. 271).

Even though macromarketing and other business/management scholars have provided conceptual models that deal with the relationships between various macro and micro factors and ethical decision making, very little has been done to demonstrate the role of macro factors. For example, the general theory of marketing ethics (Hunt and Vitell 1986, 1993), one of the most prominent and comprehensive ethical models in business, indicates that in addition to being affected by the decision maker's personal characteristics, ethical decisions managers make are largely affected by a variety of contextual, situational, and macroenvironmental factors. More specifically, the model posits that the general business environment (i.e. professional, organizational, or industrial), cultural environment (e.g. a specific religion), and legal and political systems may shape ethical decisions.

The review of the relevant literature suggests that even though the general theory of marketing ethics conceptually recognizes the important relationships between various macro factors (such as the economic, competitive, political, and legal environments) and managers' decisions, empirical studies have largely focused on situational, organizational, and/or individual factors (Burns and Kiecker 1995; Donoho et al. 1999; Hunt and Vasquez-Parraga 1993; Mayo and Marks 1990; Menguc 1998; Singhapakdi and Vitell 1990; Vitell, Singhapakdi, and Thomas 2001). The role of other macro issues such as the economic, political, and legal environments have largely remained unstudied.

Our objectives in this article are to respond to the methodological calls made by Dixon (2002), Fisk (2006), Layton and Grossbart (2006), and the ethics-research-related calls made by Murphy and Laczniak (1981), Laczniak (1993), Nill and Schibrowsky (2007), and Laczniak and Kennedy (2011). More specifically, we aim to contribute to the macromarketing investigation by introducing the Bayesian network methodology and demonstrating its added value through a macro/empirical analysis of the political, legal, and other environmental factors surrounding managers' ethical decision making.

Using World Economic Forum (WEF) data collected from more than 42,000 executives in 148 countries, and through the BN methodology, we investigate how various structural (e.g. economic, political, legislative, competitive) factors relate to the ethical behavior of firms (EBOF). The unique design of our study allows us to compare these relationships based on the country classification (i.e. stage of development) identified by the WEF. In this way, we are able to demonstrate how issues related to businesses' legal and political environments are linked to the EBOF operating in countries at different stages of development. The next section provides an overview of the use of Bayes theory in the marketing literature and a detailed account of the BN methodology. We then report our findings and discuss their implications. We also provide a discussion on the added value of the BN methodology for macro-level decision makers as well as about the limitations of the methodology.

\section{The Use of Bayes Theory (Bayesian Statistics) in Marketing}

Although Bayesian statistics were introduced around the mid18th century, their first appearance in the marketing literature only dates back to the late 1950s. In his decision-theoretic text, Schlaifer (1959) introduced Bayesian statistics to business students. In the subsequent decades, Green and colleagues published papers to both explain the nature of Bayesian decision theory and to demonstrate its applications for decision making in marketing (Green and Frank 1966; Alderson and Green 1964). Following in Green's footsteps, other researchers have offered solutions to a variety of marketing problems using Bayesian approaches.

For example, by using a hierarchical Bayesian framework, Yang and Allenby (2003) investigated the interdependence between consumer preferences and choices (i.e. the relationship between a consumer's preference and the preferences of others in the same network). Using a similar methodological approach, Kim, Allenby and Rossi (2002) developed a model to estimate demand for variety (i.e. consumer demand for products where a variety of colors, flavors, types, and models. are available). In determining the sales increase in packaged goods, Allenby et al. (2004) introduced a Bayesian choice model that is capable of dealing with discrete quantities and quantity discounts.

As one of the most promising theories for dealing with uncertainty, Bayesian ideas have been widely applied in social sciences, health sciences, and engineering, but to a lesser extent in marketing. As evident in the above studies, many techniques incorporate Bayes theory to deal effectively with uncertainty, such as the Bayesian logit model, the Bayesian hierarchical model, and Bayesian decision trees. Bayesian networks, however, are different from the above statistical methods. In BNs, Bayesian probabilities are used to model the dependencies within a knowledge domain. They are used to determine the posterior marginal probability distributions for the variables of interest, given the observed information. Bayesian networks merge graph theory with Bayes theory to analyze the relations between variables in a given domain. Such an analysis, unlike the other Bayesian methods, allows for a system-level exploration, including observing system changes and making scenario analyses.

\section{The Bayesian Network Method}

This section takes a step-by-step approach to explaining the Bayesian network method in-depth, and also provides information about the dataset used in our study. Bayesian networks, as one of the most commonly used probabilistic models, are especially useful in modeling uncertainty in a domain and have been applied particularly to problems that require diagnosis based on a variety of types of input data in a system of variables (Nicholson et al. 2008). It is a graphical model that efficiently encodes the joint probability distribution for a large set of variables (Heckerman 1995). 
Bayesian network theory is well established, and the method has been applied with success in various domains of business and economics (Ahn and Ezawa 1997; Cinicioglu, Shenoy, and Kocabasoglu 2007; Fusco 2008; Jensen, Toftum, and Friss-Hansen 2009; Scuderi and Clifton 2005), medicine (Nicholson et al. 2008), ecology and environmental issues (Dambacher et al. 2007; Bromley et al. 2005), and transportation (Cinicioglu, Onsel, and Ulengin 2012). A detailed analysis of the BN-model literature can be found in Korb and Nicholson (2011).

\section{Literature-Supported Rationale for Using BN}

There exists a growing interest in BN because of its semantic clarity and understandability, its ease of acquisition and incorporation of prior knowledge, and the ease of integration with optimal decision-making models (Friedman et al. 2000). Many reasons account for the $\mathrm{BN}$ method's popularity in literature:

(1) BNs not only provide a clear graphical structure that most people find intuitive to understand, but also make it possible to conduct flexible inference based on partial observations, which allows for reasoning (Onisko 2008). Performing what-if queries is easy to conduct and understand with BNs (Lauria and Duchessi 2007). Such queries may include backward inference (diagnostic reasoning) or forward inference (predictive reasoning) (Blodgett and Anderson 2000). When used in this way, BNs can be thought of as powerful probabilistic inference engines. The possibility of making two-way inferences is particularly valuable for managers (decision makers).

(2) Compared to regression- and structural equation-based models (SEMs), in which the correlation between the variables leads to multicollinearity and lack of robustness of model fit, BNs leverage the mutual correlation between variables to define the conditional probability distribution (Sebastiani and Perls 2008). In many multivariate analysis methods (including regression) correlations among the variables may jeopardize the models' robustness and therefore considered a problem. In the BN analysis, correlations among variables are used to establish conditional probability distributions, and thus deemed desirable.

(3) Regression and SEM-based models also only give a description of theoretical constructs, while BNs provide predictions described in terms of probabilities and percentages, which help to conduct effective analysis, including predicting and diagnosing observed variables in a system (Anderson and Vastag 2004). Structural equation model techniques are used for explaining rather than estimating variable values (Lauria and Duchessi 2007). That is, SEMs are powerful for establishing theoretical relationships among variables but do not allow any further scenario analyses. With BNs, researchers not only establish the relationships but also observe the impact of a change in any variable on the probability change in all other variables of the system.

(4) Regression and SEM-based models are generally best suited for modeling 20 or fewer measured variables, but BNs have the capability to be applied to very large processes, with potentially thousands of variables (Anderson and Vastag 2004). The size of the model (or the number of variables) is not a restriction for BNs, which makes them well-suited method for macro-level (data) analysis.

(5) Regression and SEM-based models attempt to model deterministic relationships between variables by assuming normality and linearity. BNs seek to represent the probability distribution of the variables in question, thus, no functional form or variable distribution assumptions are necessary for probabilistic inference (Blodgett and Anderson 2000; Clarke, Leuridan, and Williamson 2013). Bayesian networks can handle non-linear relations between variables, which is not possible with regression or SEM methods (Anderson and Vastag 2004).

(6) Regression and SEM-based models offer traditional measurement and statistical outputs. BNs use probabilities, which are more easily understood than standardized regression weights (Blodgett and Anderson 2000). As a result, BN outputs are much easier to communicate to decision makers.

(7) Regression and SEM-based models force the selection of one or more dependent variables and limit the estimation for these variables. BNs can estimate the values of all variables in a network (Cinicioglu, Onsel, and Ulengin 2012; Lauria and Duchessi 2007).

In addition to various strengths, BNs also suffer from certain limitations. We provide an elaborated discussion on their methodological weaknesses in the Discussion section.

\section{Bayesian Network Structure}

A Bayesian network is a directed acyclic graph where the nodes represent variables and the directed arcs define statistical relationships (Fenton et al. 2010). The graphs are representations of joint probability distributions (Korb and Nicholson 2011). If there is a directed arc from a variable $\mathrm{X}_{1}$ to a variable $\mathrm{X}_{2}$, the arc indicates that a value taken by $\mathrm{X}_{2}$ depends on the value taken by $\mathrm{X}_{1}$, or $\mathrm{X}_{1}$ "influences" $\mathrm{X}_{2} . \mathrm{X}_{1}$ is called the parent of $X_{2}$ and $X_{2}$ the child of $X_{1}$. Nodes without parents are defined through their prior probability distributions, while nodes with parents are defined through conditional probability distributions. Conditional independence relationships are implicit in the directed acyclic graph: all nodes are conditionally independent of their ancestors, given their parents.

Consider a BN containing $n$ nodes, namely, $X_{1}$ to $X_{n}$. A particular value in the joint distribution is represented by $\mathrm{P}\left(\mathrm{X}_{1}=\mathrm{x}_{1}, \mathrm{X}_{2}=\mathrm{x}_{2}, \ldots, \mathrm{X}_{\mathrm{n}}=\mathrm{x}_{\mathrm{n}}\right)$. The chain rule of 
probability theory allows factoring joint probabilities, as given in the following formula. By this formula, the answer that the system will give under some certain probability states can be calculated.

$$
\begin{aligned}
P\left(X_{1}=x_{1}, X_{2}\right. & \left.=x_{2}, \ldots, X_{n}=x_{n}\right)=P\left(x_{1}, x_{2}, \ldots, x_{n}\right) \\
& =P\left(x_{1}\right) \cdot P\left(x_{2} \mid x_{1}\right) \cdot \ldots \cdot P\left(x_{n} \mid x_{1}, \ldots, x_{n-1}\right) \\
& =\prod_{i} P\left(x_{i} / x_{1}, \ldots, x_{i-1}\right)
\end{aligned}
$$

The structure of a BN implies that the value of a particular node is conditional only on the values of its parent nodes, so the formula becomes:

$$
P\left(x_{1}, x_{2}, \ldots, x_{n}\right)=\prod_{i} P\left(x_{i} / \operatorname{Parents}\left(x_{i}\right)\right)
$$

\section{The Stages of Bayesian Network Construction}

Bayesian networks are constructed in an iterative multi-stage process (Dambacher et al. 2007). In the first stage, the analyst identifies the important variables (nodes). This stage is usually based on existing literature (Mase 2008; Dogan 2012), expert consultation (Cinicioglu, Onsel, and Ulengin 2012; Nadkarni and Shenoy 2004; Stamelos et al. 2003), and/or the analyst's experience (Lin and Haug 2008). The literature does not favor any of the mentioned variable selection methods, accepting all three as legitimate. Expert judgment can be elicited in two ways: In structured methods, concepts in the maps are defined a priori by the modelers and are imposed on the experts (Nadkarni and Shenoy 2004). In unstructured methods, concepts emerge from the data or from the expert's narrative.

In the second stage, the network structure must be constructed. This step includes capturing qualitative relationships between variables. Three approaches are used in the literature to build a BN (Lin and Haug 2008). The first one is "all human-composed" in that human experts provide the nodes, arcs, and conditional probabilities. As the complexity of the network increases, this process can become very demanding and time consuming. The crime-risk factors analysis conducted by Boondao (2008), the software safety standards investigated by Gran (2002) are three examples of all human-composed $\mathrm{BN}$ structures. The second approach combines a "humancomposed structure and machine-learned parameters," in which human experts provide the causal relationships, the network structure is designed using this information, and the parameters can be learned from the data. The medical diagnosis system developed by Onisko (2008), called "the Hepar Project"; the ethical behavior of firms analyzed by Ekici and Onsel (2013), and the decision support tool developed by Ulengin et al. (2014) are examples of this type of BN approach. The third approach (the one used in this study) can be called an "all machine-learned" approach, and the network structure can be learned from data and the parameters. This approach is particularly useful when no domain expert is available to provide the structure or the probabilities, when the problem is too complex to be solved entirely by hand, and when the domain expert's time is limited. This approach also reduces the chance of

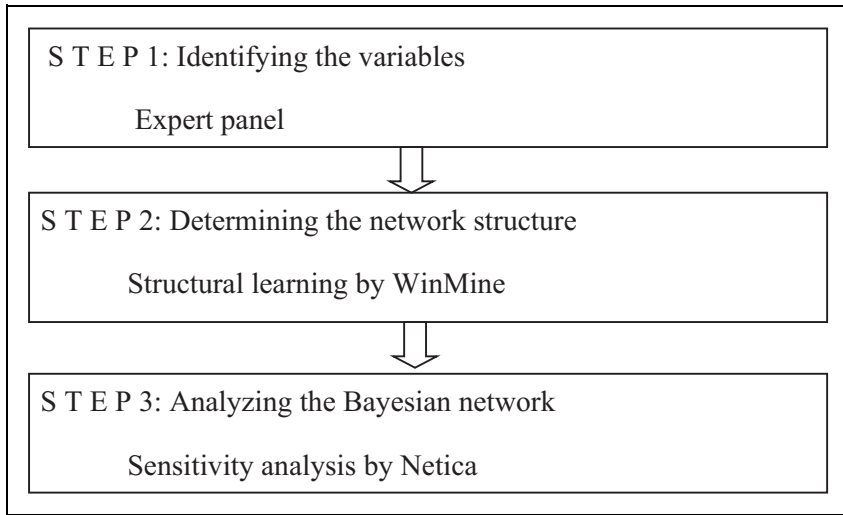

Figure I. Methodology framework.

cognitive and emotional biases, which may be introduced by (human) experts, and considers each theoretically possible configuration of variables (Pourret 2008). In this type of BN, because domain experts are not involved in constructing the network model, the arcs and their directions show conditional dependency relations rather than direct causality between parent and child nodes. Fusco (2008) used this approach for modeling socio-demographic and urban dynamics during the 1990s in the coastal region of South-Eastern France, while Ibarguengoytia, Sucar, and Vadero (2008) used it for sensor validation. Lee, Park, and Shin (2009) developed a project risk management procedure by learning the BN structure from data.

After specifying the structure of the network, the next step is to quantify the relationships between connected nodes, which is done by specifying a conditional probability distribution for each node (Korb and Nicholson 2011). Initially, all possible combinations of the values of the parent nodes must be examined (called "instantiation"). Then, for each distinct instantiation of parent node values, the probability that the child will take each of its values must be specified.

\section{The Study}

This section illustrates the "all machine-learned" BN approach by using the context of ethics. The data for this study come from part of the Executive Opinion Survey (EOS) collected by the WEF's Global Competitiveness Network members. The network has over 150 partners around the world and conducts its EOS from a representative sample of executives in each country. To determine the scores for each economy for each survey question, the WEF edits and aggregates the individual responses (Browne, Geiger, and Gutknecht 2013). The data in our study are based on the aggregated WEF data, which use the EOS as well as hard data. The countries the WEF analyzes differ slightly each year, but the number of countries analyzed in 2010, 2011, and 2012 (and so in our study) is 148.

Figure 1 summarizes the framework of the BN methodology used in this study. In the first step, factors related to the EBOF variable were determined by a panel of business ethics experts. In the second step, we developed a BN through structural learning using WinMine software (Heckerman et al. 2000), created 
by Microsoft Research ${ }^{1}$. In the last step, we conducted a number of scenario and sensitivity analyses to guide managers and policy makers in their attempts to understand and improve the ethical business climate in their countries.

\section{Identifying the Factors}

Since 2005, the WEF has based its competitiveness analysis on the Global Competitiveness Index (GCI), a comprehensive tool that measures the microeconomic and macroeconomic foundations of national competitiveness (Sala-i Martin et al. 2012). The GCI takes into account a weighted average of many different components, each measuring a different aspect of competitiveness. These components are grouped into 12 pillars. In this study, we used the components of the first pillar (Institutions) to analyze the EBOF.

For the first stage of the BN method, we conducted a survey to determine the variables that would serve as the basis for analyzing EBOF. From among the 20 concepts of the GCI's Institutions pillar, we asked seven academics with expertise in business ethics to choose concepts (variables) that they feel are related to EBOF. The full list of concepts and items used in their measurement are given in Table 1. Our approach is neither a structured nor an unstructured method (Nadkarni and Shenoy 2004), but what we call a "semi-structured method." We selected our experts from different parts of the world (two from the United States, two from Europe, two from the Middle East, and one from Asia) and all either teach undergraduate- and/or graduate-level business or marketing ethics courses and/or publish regularly in major business ethics journals. The survey was administered via email. Many of the 20 concepts received at least one or two votes from the experts, but eight concepts in particular received a vote from all seven experts. Hence, those are the concepts chosen for our analysis (see Table 2). To identify the relationship between a country's "Cluster" (stage of economic development) and EBOF, we introduced a Cluster variable into the analysis.

We classified the countries according to the $2012 \mathrm{WEF}$ report. As evident from Table 3, three stages of country development incorporate two transition stages, thus resulting in five groups of countries (Sala-i Martin et al. 2012). The development stages are mostly based on gross domestic product (GDP) per capita. GDP is not the sole criterion for economies with a high dependency on mineral resources, but such countries comprise a relatively small percentage of the total countries involved.

Sala-i Martin et al. (2012) state that countries in the first stage of development are mainly factor driven and compete based on their factor endowments - primarily low-skilled labor and natural resources. Companies acting in such countries compete on the basis of price, and sell basic products or commodities, with their low productivity reflected in low wages. Companies in efficiency-driven countries, on the other hand, develop more-efficient production processes and increase product quality. Finally, companies in innovation-driven countries compete by producing new and different goods through new technologies and/or the most-sophisticated production processes or business models. Wages are much higher in such countries, but these wages and the associated standard of living can be sustained only if businesses can compete by offering new and/or unique products, services, models, and processes.

\section{Determining the Network Structure}

In the second stage of our methodology, to determine and analyze the relationships between EBOF and the other nine variables, we constructed a network model using the BN method. To identify the BN from the data, the data were first transformed into a system that classified the ratings of each of the ten variables into five main probability states: very low, low, middle, high, and very high. Each variable has a different width of range because each has different minimum and maximum values. During this transformation, also called discretizing, we calculated the difference between the maximum and minimum values for each variable and divided the related range into five intervals, resulting in five states of the discrete version of the variable (Table 4). Discretization is required for $\mathrm{BNs}$, especially when the structure is learned from data, as in our study.

After determining the possible states for each variable, we used WinMine to identify the BN that represents the dependency relations between the EBOF's fundamental factors. The data were first divided into two parts: $80 \%$ for training and $20 \%$ for testing. Given the dataset, the structure learning process of WinMine works to find the most probable model structure from among the set of all possible model structures (Achumba et al. 2012). The provided model is the one that best describes the conditional independences in the data set.

The search algorithm underlying WinMine works to identify the structure with the highest logscore value through its heuristical comparative exploration of the search space. It makes successive arc changes (i.e. the presence of an arc and/or its direction) to the network, and evaluates the merit of each change (Chickering, Geiger, and Heckerman 1995). The dataset, the scoring function (logscore), and the search space constitute the inputs to the search algorithm, while the output is a network that maximizes the score and the probability of the most probable structure given the dataset. The related $\mathrm{BN}$ is given in Figure 2.

The BN learned in the training set was tested using the test data, where the efficiency of the learned model was evaluated using the log score (Cinicioglu, Shenoy, and Kocabasoglu 2007), a quantitative criterion that compares the quality and performance of learned BNs. The formula for calculating the $\log$ score is given as follows, where $\mathrm{n}$ is the number of variables, and $\mathrm{N}$ is the number of cases in the test set:

$$
\left.\operatorname{Score}\left(x_{1}, \ldots, x_{N}\right)=\sum_{i=1}^{N} \log _{2} p\left(x_{i} \mid \bmod e l\right)\right) / n N
$$

In this study, the log score of the generated model is found to be -0.8978 , meaning that on average, the log probability each 
Table I. List of 20 Variables (Concepts) Comprising the "Institutions Pillar" of the Global Competitiveness Index (GCl).

Variables
01 Property rights
02 Intellectual property protection
03 Diversion of public funds

04 Public trust in politicians

05 Irregular payments and bribes

06 Judicial independence

07 Favoritism in decisions of government officials

08 Wastefulness of government spending

09 Burden of government regulation

10 Efficiency of legal framework in settling disputes

II Efficiency of legal framework in challenging regulations

12 Transparency of government policymaking

13 Government provision of services for improved business performance

14 Business costs of terrorism

I5 Business costs of crime and violence

16 Organized crime

17 Reliability of police services

I8 Ethical behavior of firms

19 Strength of auditing and reporting standards

20 Efficacy of corporate boards

2I Protection of minority shareholders' interests

22 Strength of investor protection
Related Questions

How would you rate the protection of property rights, including financial assets, in your country? [I = very weak; 7 = very strong $]$

How would you rate intellectual property protection, including anti-counterfeiting measures, in your country? [I = very weak; 7 = very strong $]$

In your country, how common is diversion of public funds to companies, individuals, or groups due to corruption? [ 1 = very common; 7 = never occurs $]$

How would you rate the level of public trust in the ethical standards of politicians in your country? [I = very low; 7 = very high $]$

Average score across the five components of the following Executive Opinion Survey question: In your country, how common is it for firms to make undocumented extra payments or bribes connected with (a) imports and exports; (b) public utilities; (c) annual tax payments; (d) awarding of public contracts and licenses; (e) obtaining favorable judicial decisions? In each case, the answer ranges from I (very common) to 7 (never occurs)

To what extent is the judiciary in your country independent from influences of members of government, citizens, or firms? [I = heavily influenced; $7=$ entirely independent $]$

To what extent do government officials in your country show favoritism to well-connected firms and individuals when deciding upon policies and contracts? [ $\mathrm{I}=$ always show favoritism; 7 = never show favoritism]

How would you rate the composition of public spending in your country? [ 1 = extremely wasteful; 7 = highly efficient in providing necessary goods and services]

How burdensome is it for businesses in your country to comply with governmental administrative requirements? ( $I$ = extremely burdensome; 7 = not burdensome at all]

How efficient is the legal framework in your country for private businesses in settling disputes? [I = extremely inefficient; $7=$ highly efficient $]$

How efficient is the legal framework in your country for private businesses in challenging the legality of government actions and/or regulations? [ $1=$ extremely inefficient; $7=$ highly efficient]

How easy is it for businesses in your country to obtain information about changes in government policies and regulations affecting their activities? [I = impossible; 7 = extremely easy]

To what extent does the government in your country continuously improve its provision of services to help businesses in your country boost their economic performance? [ $1=$ not at all; 7 = extensively]

To what extent does the threat of terrorism impose costs on businesses in your country? [I = to a great extent; $7=$ not at all $]$

To what extent does the incidence of crime and violence impose costs on businesses in your country? [I = to a great extent; $7=$ not at all $]$

To what extent does organized crime (mafia-oriented racketeering, extortion) impose costs on businesses in your country? [ I = to a great extent; $7=$ not at all]

To what extent can police services be relied upon to enforce law and order in your country? [ $\mathrm{I}=$ cannot be relied upon at all; $7=$ can be completely relied upon $]$

How would you compare the corporate ethics (ethical behavior in interactions with public officials, politicians, and other enterprises) of firms in your country with those of other countries in the world? [I = among the worst in the world; $7=$ among the best in the world]

In your country, how would you assess financial auditing and reporting standards regarding company financial performance? [ 1 = extremely weak; 7 = extremely strong]

How would you characterize corporate governance by investors and boards of directors in your country? [ I = management has little accountability to investors and boards;

$7=$ investors and boards exert strong supervision of management decisions]

In your country, to what extent are the interests of minority shareholders protected by the legal system? [I = not protected at all; 7 = fully protected $]$

Strength of Investor Protection Index on a 0-10 (best) scale variable assigns to the given value in the test case (given the value of other variables in the provided model) is $53.67 \%$. That is, with the learned $\mathrm{BN}$ model (the predictions that have been made on the test groups) the true prediction is $53.67 \%$.
Using WinMine, the provided and marginal models can also be compared, based on the "lift-over-marginal" score, which is the difference between the log scores of the provided model and the marginal model. In the same way that a regression 
Table 2. Variables Related to Ethical Behavior of Firms (EBOF).

Intellectual property protection (IPP)

Irregular payments and bribes (IPAB)

Judicial independence (JI)

Favoritism in decisions of government officials (FIDOGO)

Transparency of government policymaking (TOGP)

Strength of auditing and reporting standards (SOARS)

Efficacy of corporate boards (EOCP)

Strength of investor protection (SOIP) model is more accurate than a simple baseline model chosen in the form of a mean dependent value, the "lift over marginal" log-score provides information on how well the model fits the data (Cinicioglu, Shenoy, and Kocabasoglu 2007). In this sense, the provided model is the one that best describes the conditional independences, while the marginal model does not take into account the conditional probability information.

If the lift-over-marginal score is positive, it can be concluded that the provided model outperforms the marginal

Table 3. Stages of Development Used in the Study (adopted from WEF 2012).

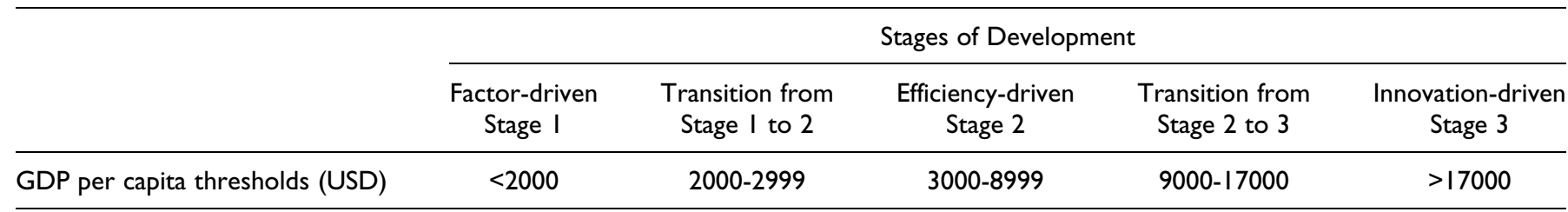

Table 4. Variables' Interval States.

\begin{tabular}{|c|c|c|c|c|c|c|c|c|c|c|c|c|c|c|c|c|c|}
\hline \multicolumn{2}{|c|}{$\begin{array}{l}\text { Intellectual } \\
\text { property } \\
\text { protection }\end{array}$} & \multicolumn{2}{|c|}{$\begin{array}{l}\text { Irregular } \\
\text { payments } \\
\text { and bribes }\end{array}$} & \multicolumn{2}{|c|}{$\begin{array}{c}\text { Judicial } \\
\text { independence }\end{array}$} & \multicolumn{2}{|c|}{$\begin{array}{l}\text { Favoritism in } \\
\text { decisions of gov- } \\
\text { ernment officials }\end{array}$} & \multicolumn{2}{|c|}{$\begin{array}{c}\text { Transparency of } \\
\text { government } \\
\text { policymaking }\end{array}$} & \multicolumn{2}{|c|}{$\begin{array}{l}\text { Ethical } \\
\text { behavior of } \\
\text { firms }\end{array}$} & \multicolumn{2}{|c|}{$\begin{array}{l}\text { Strength of } \\
\text { auditing and } \\
\text { reporting } \\
\text { standards }\end{array}$} & \multicolumn{2}{|c|}{$\begin{array}{l}\text { Efficacy of } \\
\text { corporate } \\
\text { boards }\end{array}$} & \multicolumn{2}{|c|}{$\begin{array}{l}\text { Strength of } \\
\text { investor } \\
\text { protection }\end{array}$} \\
\hline \multicolumn{2}{|l|}{ IPP } & \multicolumn{2}{|c|}{ IPAB } & \multicolumn{2}{|c|}{ ال } & \multicolumn{2}{|c|}{ FIDOGO } & \multicolumn{2}{|c|}{ TOGP } & \multicolumn{2}{|c|}{ EBOF } & \multicolumn{2}{|c|}{ SOARS } & \multicolumn{2}{|c|}{ EOCB } & \multicolumn{2}{|c|}{ SOIP } \\
\hline 1.57 & 2.51 & 2.20 & 3.10 & 1.28 & 2.38 & 1.70 & 2.56 & 2.22 & 3.04 & 2.38 & 3.26 & 2.60 & 3.39 & 2.58 & 3.24 & 0.00 & 1.94 \\
\hline 4.40 & 5.34 & 4.91 & 5.82 & 4.59 & 5.70 & 4.28 & 5.14 & 4.67 & 5.48 & 5.03 & 5.92 & 4.98 & 5.78 & 4.57 & 5.24 & 5.82 & 7.76 \\
\hline 5.34 & 6.28 & 5.82 & 6.72 & 5.70 & 6.80 & 5.14 & 6.00 & 5.48 & 6.30 & 5.92 & 6.80 & 5.78 & 6.57 & 5.24 & 5.90 & 7.76 & 9.70 \\
\hline
\end{tabular}

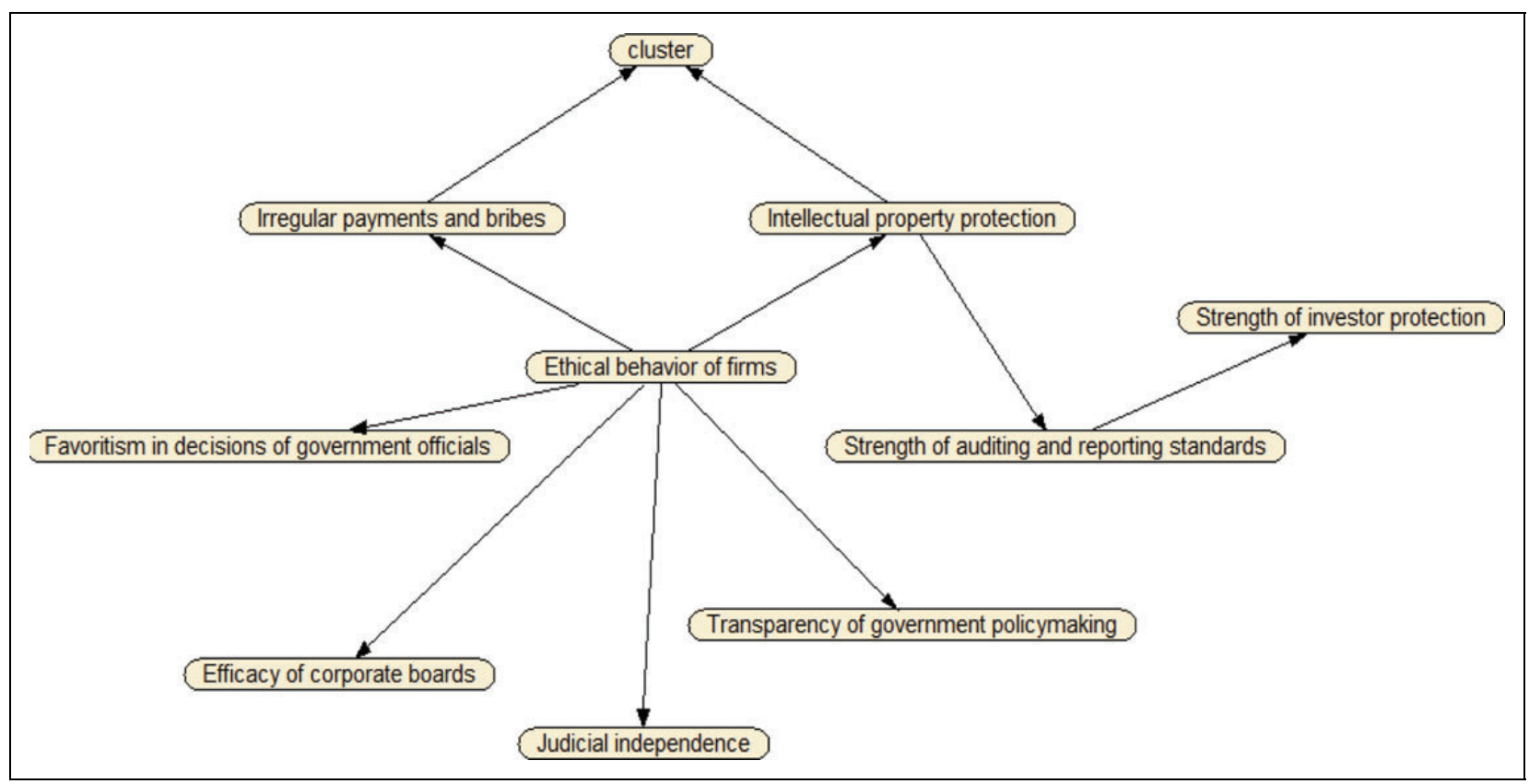

Figure 2. Bayesian network model. 


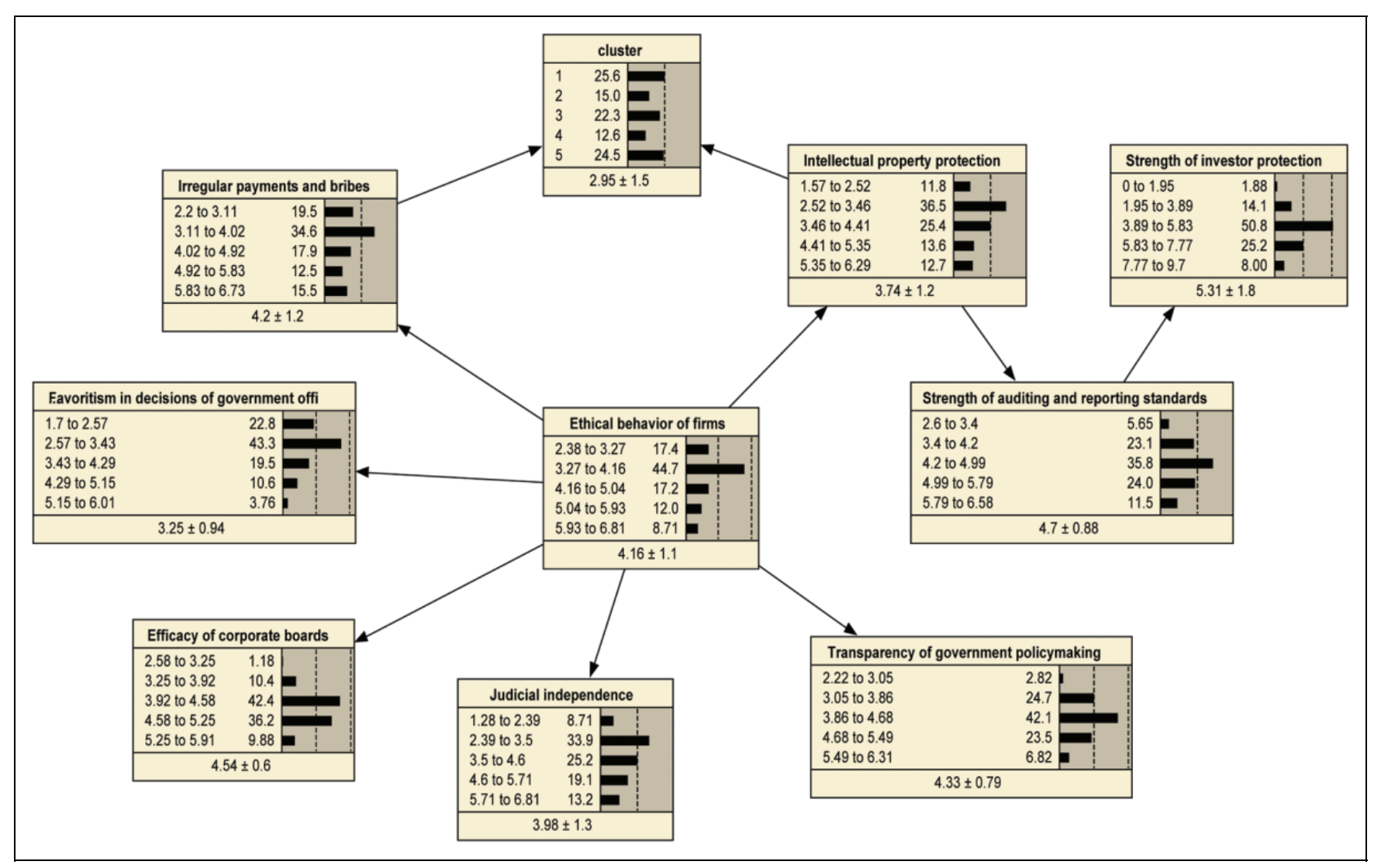

Figure 3. Bayesian network for the entire dataset.

model in the test set. Accordingly, the lift-over-marginal value obtained by our model is 0.5547 , meaning that the predictive capacity of the provided model is about $17.13 \%$ better than the marginal model. This result indicates that the provided $\mathrm{BN}$ model effectively represents the dependency relations of EBOF's fundamental factors.

\section{Analyzing the Bayesian Network}

Once a BN is constructed, it can be used to make inferences about the model's variables (Nadkarni and Shenoy 2004). To make these inferences and to perform parameter learning, in the last step of the methodology, the BN that was structured in the second step is created again, this time using Netica software (see www.norsys.com). The parameter learning that takes place in Netica is the process of automatically determining a representative Bayes net, given data in the form of cases (http:// www.norsys.com/WebHelp/NETICA.htm). Each case represents an example that exists or has occurred, and the case supplies the values for a set of variables. Each variable is a node in the learned net and the possible values of that variable become the node's states. Therefore, by parameter learning, the conditional probability table at each node, given the link structures and the data, is determined.

In this way, it is possible to enter evidence for the variables and observe the resulting changes (posterior probabilities) in the system. In other words, because BNs can deal with multiple variables at once, the resulting model can serve as an appropriate basis for conducting efficient scenario analyses regarding the topic of interest (Anthony 2006; Lauria and Duchessi 2007). The findings section of our paper provides examples of such scenario analyses.

The BN created using Netica and the marginal probabilities of the variables in the network are shown in Figure 3. The model consists of three components: a set of nodes representing the variables of the "business ethics" system, a set of links representing the conditional dependence between these nodes (which was determined in the first stage of the methodology), and, finally, a set of probabilities representing the belief that a node will be in a given state, given the states of the connecting nodes. Figure 3 shows the range of each state in the left section of each box, along with a number expressing the belief (probability) of that state as a percentage. In the right section of each box, bar graphs show the belief amounts. At the bottom of the box, the mean value is followed by a \pm symbol and its standard deviation.

BNs use probability calculus as a tool to understand, represent, and analyze uncertainty. The conditional probabilities of the $\mathrm{BN}$ are given in percentage values, which make the analysis of the net easier under uncertainty. That is, in our BN, for example (Figure 3), with respect to the data fed into the net, the probability of Judicial Independence (JI) is shown to be in a 


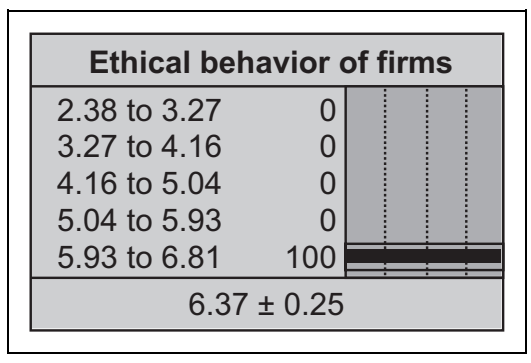

Figure 4-a. EBOF is known as being in the high state.

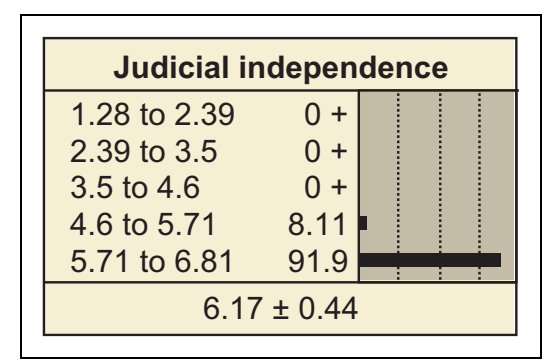

Figure 4-b. The probability distribution of $\mathrm{Jl}$ when EBOF is in high state.

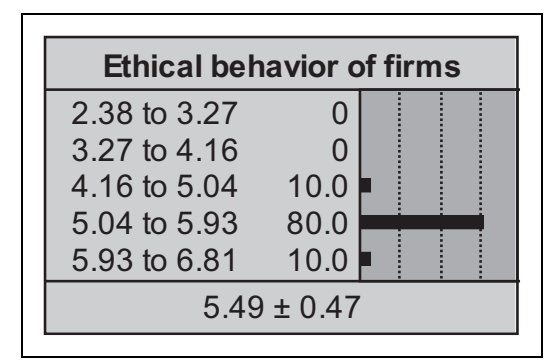

Figure 5-a. EBOF is given as virtual evidence.

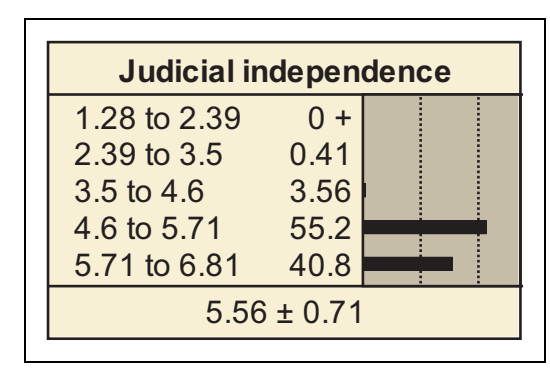

Figure 5-b. The probability distribution of $\mathrm{Jl}$ when EBOF is given as virtual evidence.

"very low" state is $8.71 \%$, whereas the probability of being in a "high" state is $19.1 \%$.

When evidence (new information about the state of the variable) is entered into EBOF (which is the parent node of JI), the percentage of JI's uncertainty changes immediately. If we know exactly that its state is "very high," it can be entered as exact evidence, as shown in Figure 4a. Then, we can observe the result (it will be very high with a $91.9 \%$ probability) in JI immediately (Figure 4b).

However, the new information might simply be any new probability distribution. Suppose, for example, we are uncertain about the state of the EBOF for a specific country. We think that the performance of this specific country tends to be high but we are only $80 \%$ sure about it, meaning that the remaining $20 \%$ uncertainty can be diversified into medium and very high states. In BNs this is known as "virtual evidence" and handled via likelihood information (Figure 5a). In the presence of the virtual evidence, there is a $55.2 \%$ chance that JI will be high and a $40.8 \%$ chance that it will be very high (Figure $5 b$ ).

In addition to allowing various scenario analyses, the $\mathrm{BN}$ model created using Netica allows researchers to perform a sensitivity analysis, which identifies the (parent) variables with the most explanatory power on another (child) variable. A detailed investigation of the latter variables is crucial because positive or negative changes in them have substantial impacts on the parent variable. In the following sections, we report the results of the scenario and sensitivity analyses for the overall model and for each country group.

\section{Findings}

\section{Overall Model}

The overall results based on the entire dataset of 148 countries show that executives around the world generally believe that (with no specified posterior probabilities) EBOF (mean+/standard deviation) is in the low state $(4.16+/-1.1)$, with a $44.7 \%$ probability. More specifically, based on the existing variables and the $\mathrm{BN}$ relationships, there is a $62.1 \%$ (low $44.7 \%$ + very low $17.4 \%$ ) probability that managers perceive the behavior of other managers as relatively low in ethics. "Relatively" is based on the state of the related variable's range, the difference between its maximum and minimum values. Because the range for EBOF is narrow (minimum of 2.38 and maximum of 6.81), despite its average value of 4.16 , the probability of EBOF being in the very low and low states is high $(62.1 \%$; see Figure 3$)$. Furthermore, the managers surveyed believe that issues related to Irregular Payments and Bribes (IPAB), Favoritism in Decisions of Government Officials (FIDOGO), Judicial Independence (JI), and Intellectual Property Protection (IPP) are all problematic aspects of the business ethics "system," that is, all receive low probabilities (where a low probability for negative concepts such as bribery and nepotism indicates poor performance). Managers draw a more-optimistic picture with respect to Efficacy of Corporate Boards (EOCB), Strength of Auditing and Reporting Standards (SOARS), and Strength of Investor Protection (SOIP) aspects of the same system.

\section{Scenario Analysis of the Overall Model}

Various scenario analyses can be provided for each of the variables included in the system (Figure 3) depending on the 
Table 5. Relationships between EBOF and other Critical Factors in the System.

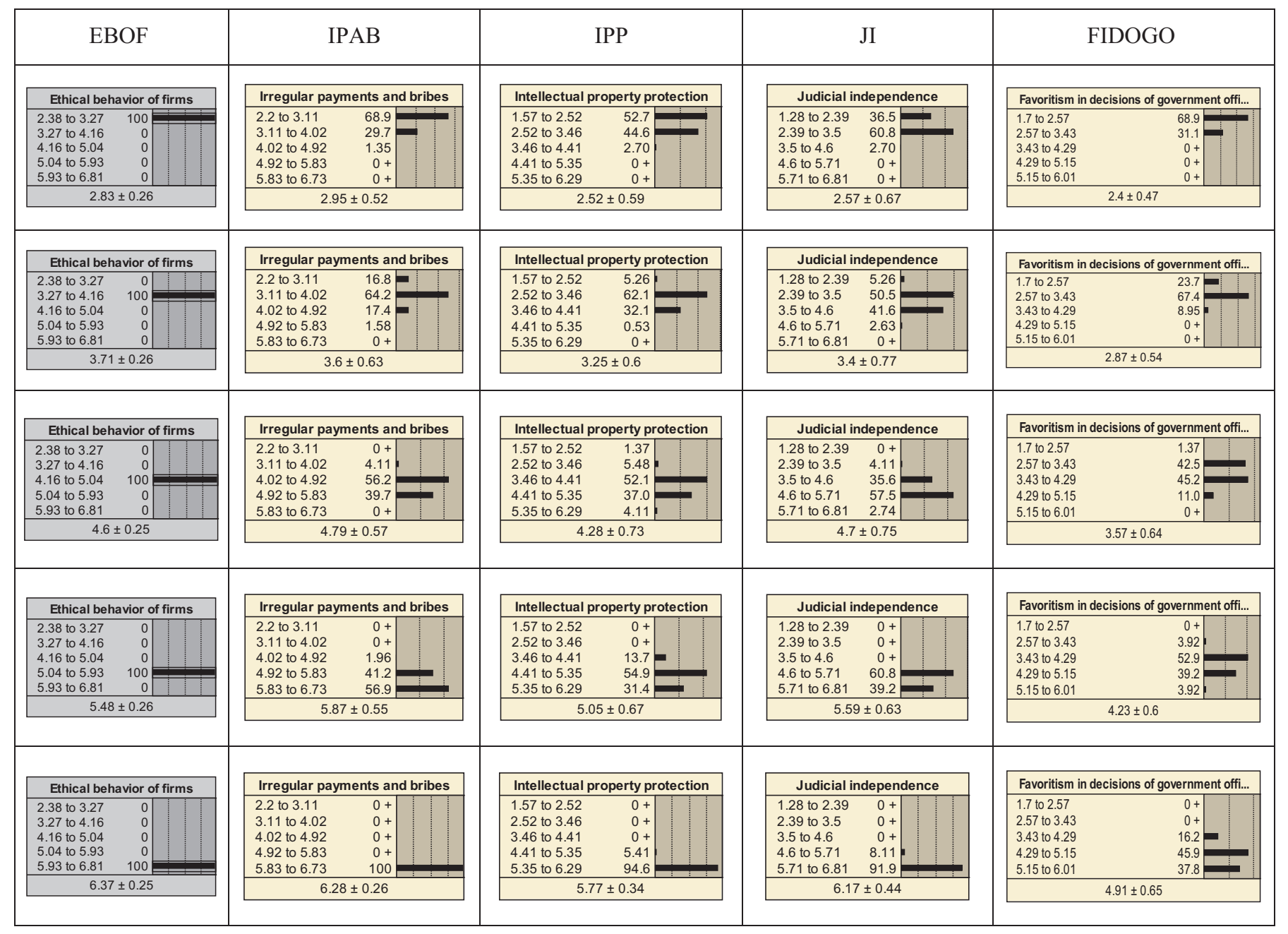

conditional probabilities values. However, because the focus of this manuscript is on ethics, we provide scenario analyses only for the EBOF variable. As explained above, ethical behavior of firms is generally perceived as relatively low. A "what-if" scenario analysis can provide more information about this belief. The second row in Table 5 demonstrates the low perception, and the following rows provide information regarding various important components of the system when EBOF is perceived as higher. More specifically, the third row suggests that when evidence about EBOF is given to the system that changes the perception from low to medium, perceptions related to Intellectual Property Protection, Favoritism in Decisions of Government Officials, and Irregular Payments and Bribes will improve from low to medium, and the posterior probabilities of Judicial Independence will improve from low to high. Similarly, when evidence about EBOF is given to the system that changes it from medium to high (see row four), perceptions related to Intellectual Property Protection and Judicial Independence will improve to high, and posterior probabilities of Irregular Payments and Bribes will improve to very high.
More specifically, the table suggests that when a low EBOF value is entered in the system (i.e. for a country where EBOF is low), there is an $81 \%(64.2 \%+16.8 \%)$ chance that Irregular Payments and Bribes, a $67.36 \%(64.2 \%+5.26)$ chance that Intellectual Property Protection, a 55.76\% (50.5\% + 5.26\%) chance that Judicial Independence, and a 91.1\% (67.4\% + $23.7 \%$ ) chance that Favoritism in Decisions of Government Officials will be perceived as low or very low (below medium). However, for a country where EBOF is perceived as medium (row 3), there is a $95.9 \%(56.2 \%+39.7 \%)$ chance that Irregular Payments and Bribes, a 93.21\% (52.1\% + 37\% + 4.11\%) chance that Intellectual Property Protection, a $95.84 \%$ (35.6\% $+57.5 \%+2.74 \%$ ) chance that Judicial Independence, and a $56.2 \%(45.1 \%+11 \%)$ chance that Favoritism in Decisions of Government Officials will be medium or better. Finally, when a high value of EBOF is entered in the system (i.e. in countries where EBOF is perceived as high - the fourth row), perceptions related to all three critical factors will be very high (a 100\% chance that the perceptions regarding IPAB, IPP, and JI will be medium or higher). Table 6 provides another interpretation of the scenario analysis summarized in Table 5, that 
Table 6. Probability (\%) of IPAB, IPP, Jl, and FIDOGO Being Medium or Higher Under Different EBOF Conditions.

\begin{tabular}{lccccc}
\hline & $\begin{array}{c}\text { Very Low } \\
\text { EBOF }\end{array}$ & $\begin{array}{c}\text { Low } \\
\text { EBOF }\end{array}$ & $\begin{array}{c}\text { Medium } \\
\text { EBOF }\end{array}$ & $\begin{array}{c}\text { High } \\
\text { EBOF }\end{array}$ & $\begin{array}{c}\text { Very High } \\
\text { EBOF }\end{array}$ \\
\hline IPAB & 1 & 19 & 93 & 100 & 100 \\
IPP & 3 & 33 & 94 & 100 & 100 \\
JI & 3 & 44 & 96 & 100 & 100 \\
FIDOGO & 0 & 9 & 56 & 96 & 100 \\
\hline
\end{tabular}

Table 7. Results of the Sensitivity Analysis for EBOF (Overall Model).

\begin{tabular}{lc}
\hline Indicator & Variance \\
\hline IPAB & 82.8 \\
JI & 79.4 \\
IPP & 78 \\
FIDOGO & 69.8 \\
TOGP & 63.5 \\
Cluster & 51.8 \\
EOCB & 51.3 \\
SOARS & 50.8 \\
SOIP & 10.4 \\
\hline
\end{tabular}

is, the probability of the critical factors (namely, IPAB, JI, IPP, and FIDOGO) being in at least the medium state. A close look at Table 6 reveals the importance of improving business ethics perceptions (through, of course, improving business ethics) from the current low level to medium.

\section{Sensitivity Analysis of the Overall Model}

The results of the sensitivity analysis (i.e. identifying factors that have the highest explanatory power) on the EBOF variable and percent variance reduction information are given in Table 7. Variance reduction is the expected reduction in the variance of the output variable $(\mathrm{Q})$ due to the value of an input variable $(\mathrm{F})$. The nodes are quantitative and have an initial distribution. When information is supplied about the state of an input node, the output node distribution may shrink towards more-probable values, reducing its variance (Nash et al. 2013). In other words, variance reduction is the difference between the variance of the output node $(\operatorname{var}(\mathrm{Q}))$ and the variance of the output node given the input node $(\operatorname{Var}(\mathrm{Q} \mid \mathrm{F}))$. The variable with the greatest variance reduction rate is expected to be the one to most change the beliefs of the observed variable and, hence, has the highest explanatory power over the output variable.

The results of the sensitivity analysis for the overall model suggest that the Irregular Payments and Bribes variable has the highest explanatory power over EBOF, followed by Judicial Independence and Intellectual Property Protection. More specifically, changes in EBOF are explained by IPAB by about $83 \%$, by JI by about $79 \%$, and by IPP by about $78 \%$, meaning that if evidence of Irregular Payments and Bribes is observed the system, this will reduce the variance in EBOF by $83 \%$.
Similarly, any evidence observation of Judicial Independence will reduce the variance in EBOF by $79 \%$. As can be seen from Figure 3, the variance of the EBOF variable is 1.1 (see the bottom of the EBOF variable box). When specific evidence (a value) of Irregular Payments and Bribes is entered in the system, the variance of EBOF drops dramatically. For example, when a value of 1 is entered (i.e. IPAB is very low), then the variance of EBOF drops from 1.1 to 0.5 ; when a value of 2 is entered (i.e. IPAB is low), then the variance of EBOF drops to 0.43. For all value levels of Irregular Payments and Bribes, the variance of EBOF drops greatly, allowing for a moreprecise estimation of EBOF.

\section{Country Group (Cluster) Analysis}

The results of the sensitivity analysis (Table 7) also suggest that EBOF is explained by the development stage of the particular country (the Cluster variable) by about $52 \%$. This result means that if evidence is given to the network about the Cluster group that we want to analyze, then the variance of EBOF will drop by $52 \%$, which will give more-accurate results. Even though no direct relation exists between the Cluster variable and EBOF, evidence observed in the Cluster node can still explain the values of EBOF. Because one of the objectives of this study is to analyze the business ethics system based on country/economic groups, we conducted additional analyses for each of three main Cluster groups identified by the WEF: Stage 1 (factor-driven), Stage 2 (efficiency-driven), and Stage 3 (innovation-driven) economies.

We first conducted the analysis for Stage 1 economies (Figure 6). To analyze the effect of the Cluster to which a country belongs, a value of 1 is entered for the Cluster variable (1 represents factor-driven economies; 3 represents efficiencydriven economies; and 5 represents innovation-driven economies). These numbers function as "evidence" of the related variable, meaning that the value (an element of the first Cluster, factor-driven countries) for the node is known. When such evidence is entered, the probabilities of the other variables are automatically updated, and as a result, for Stage 1 countries the probability of having a medium or higher (medium, high, or very high) EBOF value decreases to about $7 \%(5.82 \%+$ $0.92 \%+0 \%$; see Figure 6$)$ from about $39 \%(17.2 \%+12 \%$ $+8.71 \%$; see Figure 3).

We repeated the same analyses for Stage 2 and Stage 3 countries. The results indicate that the probability of EBOF being perceived by executives as medium or higher increases as we move from relatively less-developed economies to more-developed economies. More specifically, while the probability of having a medium or higher EBOF value is 7\% (5.82\% $+0.92 \%+0 \%$ ) in Stage 1 (less-developed) economies, the same probability becomes $21 \%(20.8 \%+0.51 \%+0 \%)$ in Stage 2 (developing) economies (Figure 7), and 86\% (17.8\% $+34.6 \%+33.9 \%$ ) in Stage 3 (developed) countries (Figure 8). A summary of Figures 6, 7, and 8 is provided in Table 8. Please note that we do not suggest or assume a causal link between economic development and EBOF values. These 


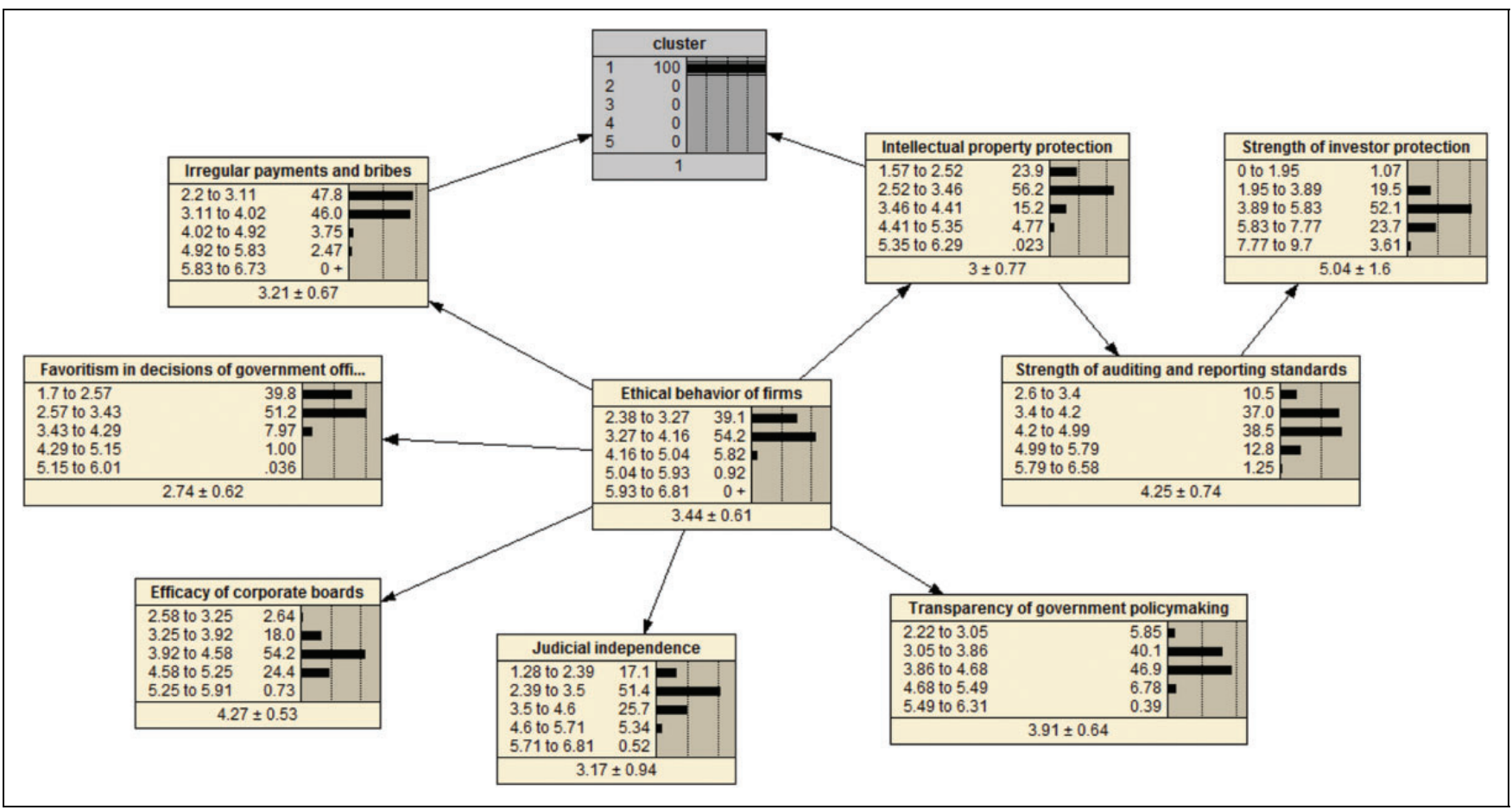

Figure 6. The $\mathrm{BN}$ for factor-driven economies.

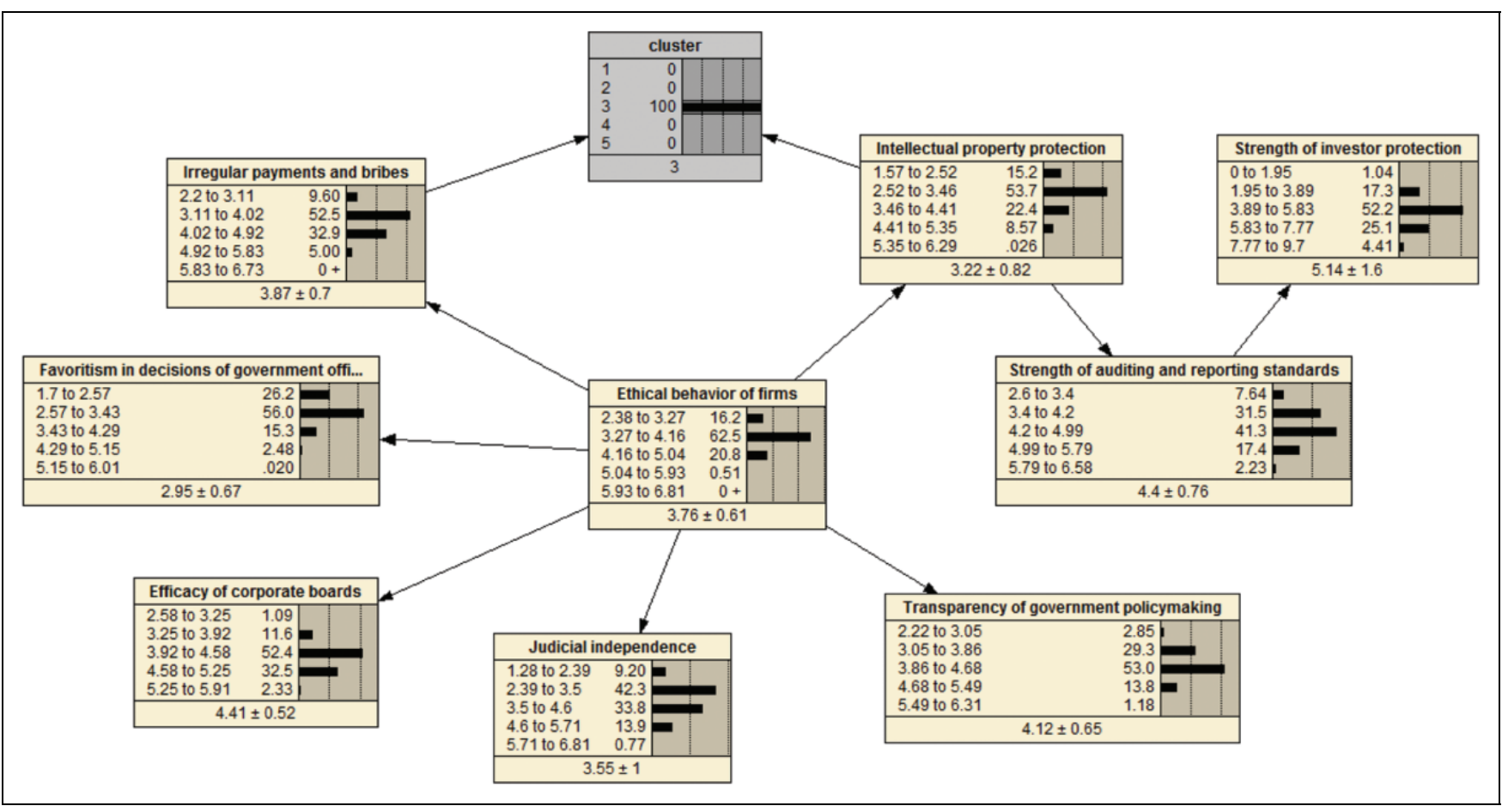

Figure 7. The $\mathrm{BN}$ for efficiency-driven economies.

figures indicate what happens when different values (economic development stages identified by the WEF) are entered in the system.

Identifying the relationship between a country's economic development stage and the ethics-related perceptions of managers who work in these countries may not be novel. To the best of our knowledge, however, identifying the explanatory power of various factors on ethics perceptions has not occurred until now. Sensitivity analysis is a powerful tool for such exploration; therefore, in the next step, we conducted a sensitivity 


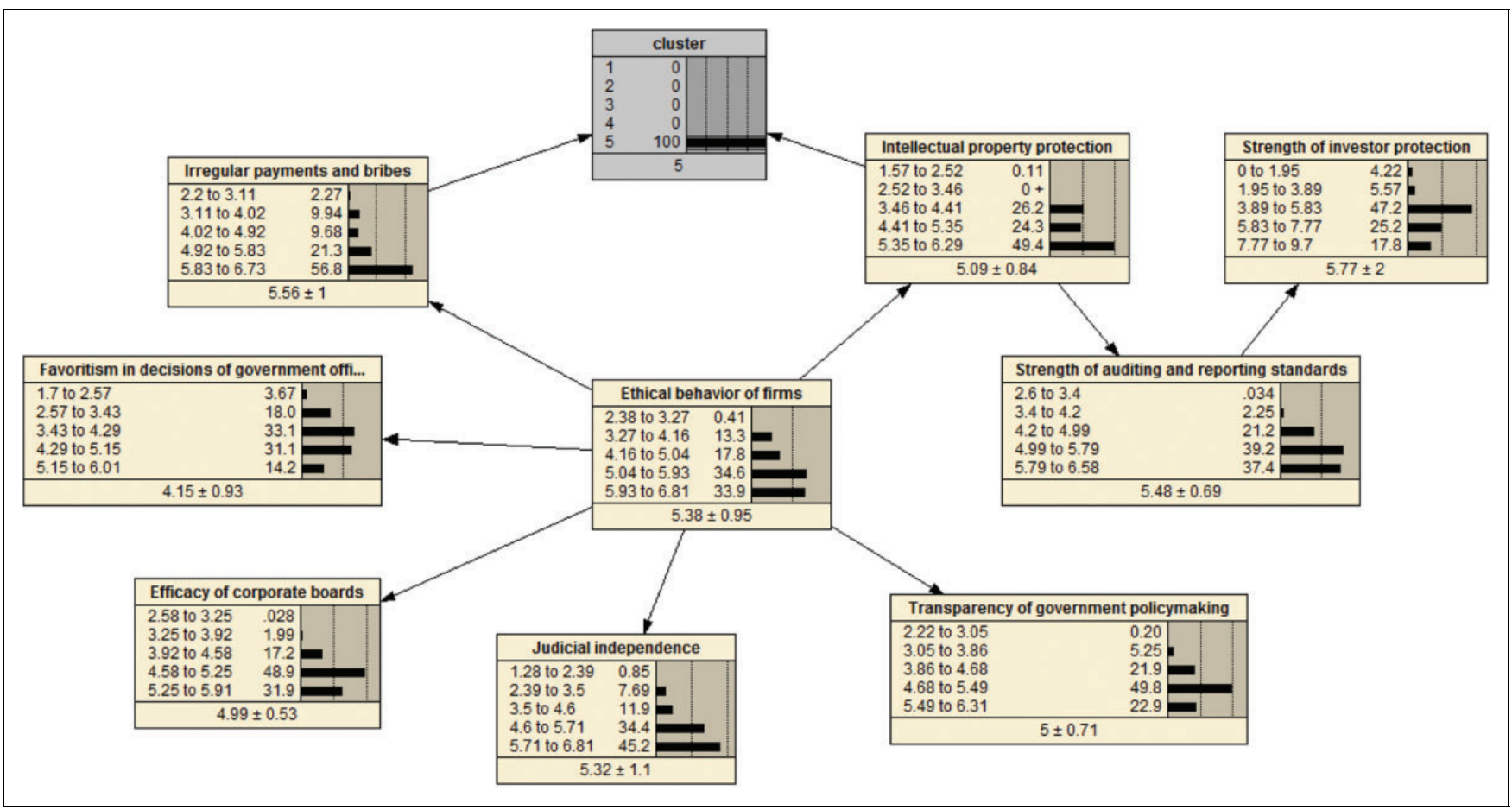

Figure 8. The BN for innovation-driven economies.

Table 8. EBOF Scores in Various Economies.

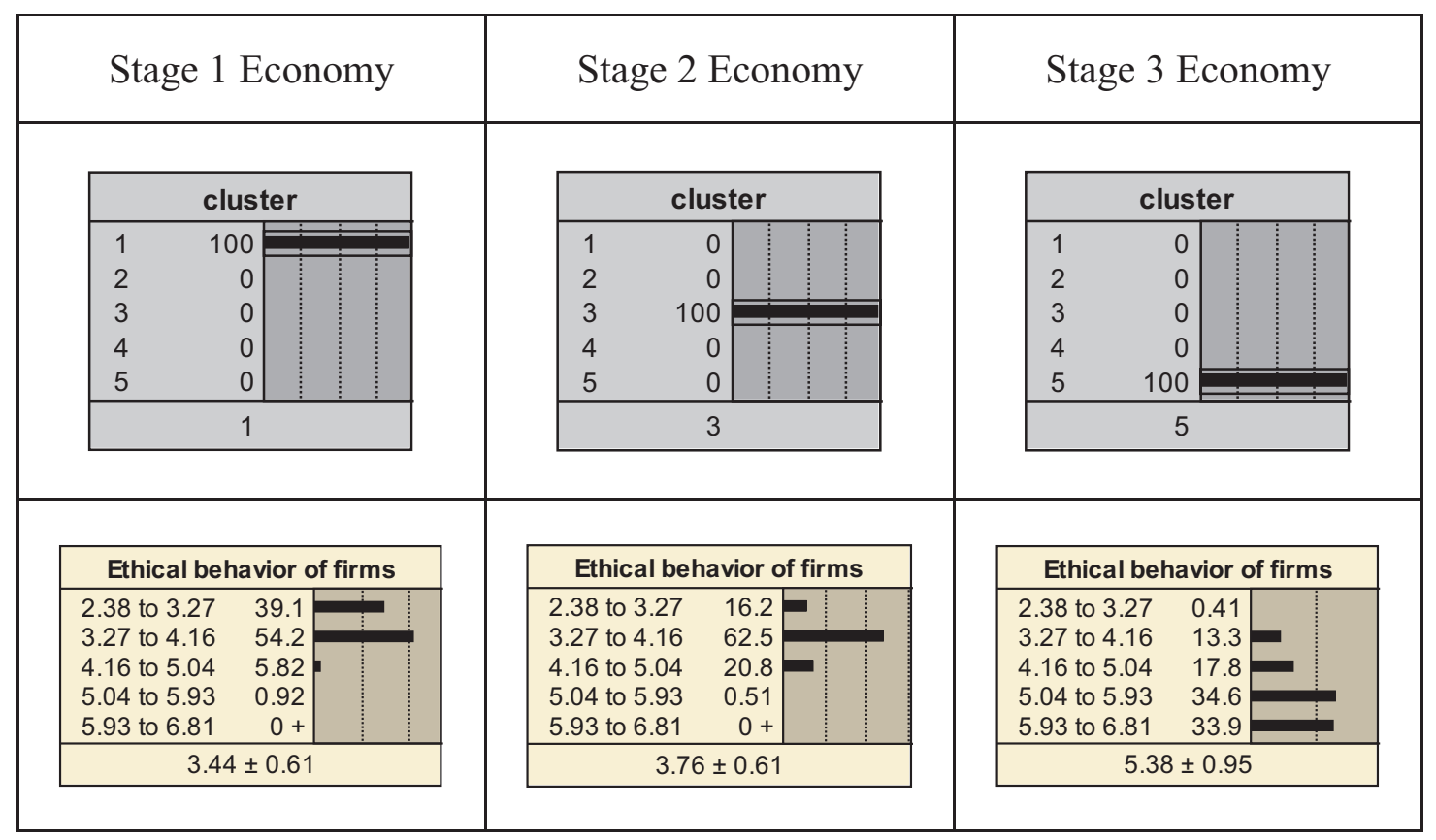

analysis for each country group. As evident from Table 9, even though the order of importance may differ, five factors (namely, IPP, JI, IPP, FIDOGO, and Transparency of Government Policymaking (TOGP)) appear as having the greatest explanatory power on ethics. More specifically, the analyses indicate that in Stage 1 countries, Intellectual Property Protection, in Stage 2 countries Judicial Independence, and in Stage 3 countries Irregular Payments and Bribes have the greatest explanatory power over managers' business ethics perceptions. The next section provides a more-detailed discussion of our findings. 
Table 9. Results of the Sensitivity Analysis for EBOF (Cluster-Based).

\begin{tabular}{|c|c|c|c|c|c|c|c|}
\hline \multicolumn{2}{|c|}{ Overall Model } & \multicolumn{2}{|c|}{ Factor-driven } & \multicolumn{2}{|c|}{ Efficiency-driven } & \multicolumn{2}{|c|}{ Innovation-driven } \\
\hline IPAB & 82.8 & IPP & 51 & ال ال & 50.1 & IPAB & 79.3 \\
\hline ار & 79.4 & IPAB & 50 & IPP & 43.9 & 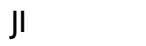 & 74.5 \\
\hline FIDOGO & 69.8 & FIDOGO & 35.3 & FIDOGO & 35.9 & IPP & 63.1 \\
\hline TOGP & 63.5 & TOGP & 33.9 & TOGP & 34.2 & TOGP & 54.3 \\
\hline EOCB & 51.3 & EOCB & 24.1 & SOARS & 20.9 & EOCB & 51.8 \\
\hline SOARS & 50.8 & SOARS & 23.3 & EOCB & 20.6 & SOARS & 28.3 \\
\hline SOIP & 10.4 & SOIP & 2.73 & SOIP & 2.46 & SOIP & 5.7 \\
\hline
\end{tabular}

\section{Discussion}

We believe that the adoption of BN methodology provides important insights for macromarketing investigation. This section first discusses additional knowledge that can be obtained through the utilization of BN methodology. We first revisit the "advantages" claims listed in the Literature-Supported Rationale for Using $B N$ section, and, in light of our findings, summarize the added value of using this method for macro-level decision making. This section also includes a discussion on the limitations of the BN methodology. Then, we elaborate the significance of our findings for the substantive domain of business ethics.

\section{Additional Knowledge Obtained through BN}

As noted, we aim to illustrate what a decision makers can do/ obtain by using the BN method that they cannot effectively do/obtain by using other methods. In summary:

- The BN model identified in this study is a representation of conditional probability distributions over a set of variables that are used for building a model for ethical behavior.

- The model represents the probability distribution of the variables without making any assumption about the functional form or variable distribution. As one can see from Figure 3, whereas the SARS variable resembles normal distribution, the CLUSTER variable does not. Yet, the system can still be analyzed effectively.

- This representation is helpful when interpreting and analyzing the system as a whole, regardless of the conditional distributions, dependencies, and correlations examined. Thus, the BN model provides a decision support tool for policy makers.

- BNs can deal effectively with partial information and uncertainty. Evidence is given to the network for the components whose values are known. Even if policy makers only have information about a country's JI level, they can still analyze the system reaction.

- BNs also allow for subjective probabilities and probabilities based on statistical data in a unified framework. Thus, qualitative and quantitative measures can be combined in making inferences. For instance, the above example includes both objective information (the particular cluster the country belongs to) and subjective information (the expected level of JI for the next year).

- In addition, this partial information might simply be any probability distribution. That is, if the policy makers are not sure about the JI level, they can enter evidence about the level of the variable in a probabilistic manner and observe how the variables in the system will be affected. The Web Appendix provides a detailed illustration regarding the use of partial information.

- By using BNs, we can analyze the impact of the evidence and make inferences about uncertain situations. Depending on the evidence entered about a country's JI level, the predicted depiction of the system shows policy makers the areas that need attention.

Bayesian networks have limitations too (Gupta and Kim 2008). In Bayesian modeling, relationships are based on association (conditional independence), and therefore, do not differentiate between causal and spurious relationships because the former cannot be ascertained from statistical data alone. The computational difficulty of calculating the probability of any branch of the network to explore an unknown network is another basic limitation of BNs (Niedermayer 2008). BNs can only deal with discrete variables (Weber et al. 2012), which may lead to a limited ability to capture the variable's original distribution.

The "acyclic directed" requirement, which is needed to carry out probability calculus, is another - and probably the most important - limitation of BNs. This means that the model must have no dynamic feedback loops, which results in feedback effects not being included in the network (Barton 
Table 10. Relationship between IPP and EBOF in Stage I Countries.

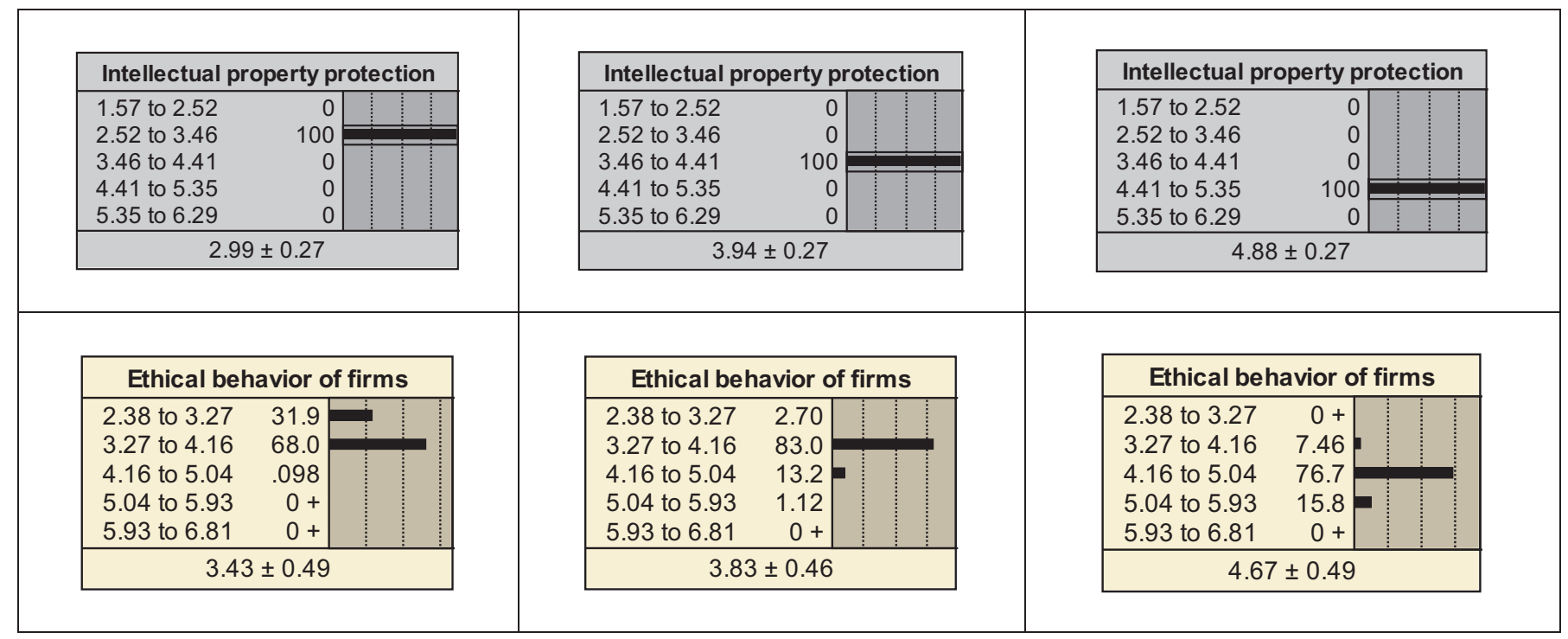

et al. 2012). Furthermore, although BNs are useful for conducting effective analysis, including predicting and diagnosing observed system variables, they are not as capable as SEMs for theoretical explanations. Another limitation of BNs is that they do not differentiate between a latent construct and its measures.

Researchers may attempt to address some of these limitations by initially constructing theoretically based models, and SEMs can be good candidates for these. Although SEMs and BNs are different, their differences can be utilized to complement each another. For example, while SEMs are based on reasoning by cause and effect (a causal modeling approach), BNs are based on the understanding that the occurrence of a cause increases the probability of an effect (a probabilistic causation approach). Moreover, although empirically validating a theoretically constructed SEM model is possible at the latent variable level, BNs offer prediction and diagnosis at the observed (individual item) level. Furthermore, although SEMs are not appropriate for modeling with new information (because the model structure may change with new data), BN structures can be perfectly trained with new data, allowing for effective scenario analyses. In addition, unlike SEMs, BNs support diagnosis. Anderson and Vastag (2004) further discuss the differences between SEMs and BNs. Establishing a hybrid model is beyond the scope of this article, but we believe that a combined/hybrid approach may be valuable in establishing causation as well as for diagnosing and predicting macromarketing phenomena.

\section{Implications for Business/Marketing Ethics}

The overall model suggests that ethical conduct is currently perceived by executives to be relatively low (see Figure 3). Implications of this perception can range from not conducting business in certain parts of the world, and therefore reducing the amount and type of products and services available to consumers and missing out on possible market, to an increase in the cost of business by "blending in" with unethical business environments (i.e. engaging in illegal business conduct). The latter option can create a vicious circle by further lowering the level of perception of EBOF in the long run. On the bright side, our scenario analyses clearly depict how each of the mostcritical components of the ethics system shapes what values the system possesses, as ethics perceptions move from low to high. From our results, therefore, policymakers and international organizations can draw insights regarding actions to be taken on various political, legal, and other market-related factors to establish a better global business ethics system, both in perception and conduct. We provide some suggestions regarding such actions in the next few paragraphs.

The results of the sensitivity analysis given in Table 9 demonstrate the importance of Intellectual Property Protection, Irregular Payments and Bribes, and Judicial Independence in the perceptions of business ethics in Stage 1 (mainly underdeveloped) countries. These findings further point out the important relationships between Intellectual Property Protection and EBOF. If we are knowledgeable about intellectual property protection perceptions in Stage 1 countries, we have a much clearer understanding about the ethical behavior of firms in these countries. As evident from Table 10, when Intellectual Property Protection is observed to be low, EBOF is observed to be low as well; there is a less than $1 \%$ probability that EBOF will be medium or higher. When Intellectual Property Protection is observed to be medium, the probability that EBOF will be medium or higher is $14.32 \%$; and when Intellectual Property Protection is observed as high, the probability that EBOF will be observed as medium or higher is $92.5 \%$. Our model is not a causal one, but the findings indicate that for Stage 1 countries, managers' ethical perceptions and intellectual property protection perceptions go hand in hand. Therefore, policy efforts to enhance intellectual property protection are likely to foster higher business ethics, and thus higher perceptions of IPP and EBOF. 
Table I I. Relationship between IPAB and EBOF, the Overall Model.

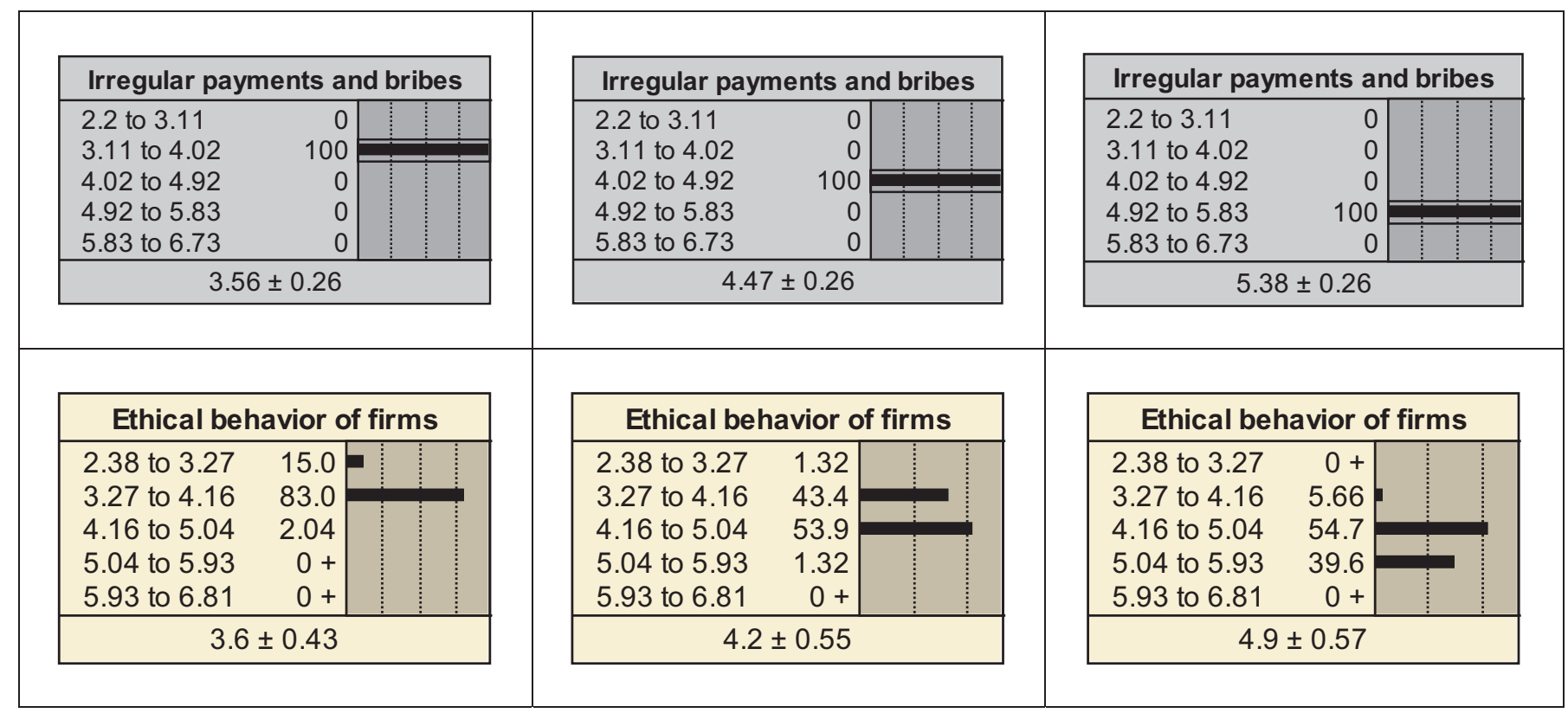

However, this suggestion is much easier made than implemented. Most of the Stage 1 countries in this study are from Africa. As many regional reports indicate, establishing an effective intellectual property perception system in Africa is extremely difficult due to various structural factors, such as cultural understandings of what is public and what is private, as well as the lack of knowledge, people, and institutions with adequate experience to handle intellectual-property-rightsrelated issues (Kameri-Mtobe 2008; Sikoyo, Nyukuri, and Wakhungu 2006). Nevertheless, local policy makers (possibly with the support of international organizations) should focus on enhancing IPP-related national infrastructure and the capacity of human resources. In addition, because litigation over intellectual property rights is quite low in most countries in Africa (Sikoyo, Nyukuri, and Wakhungu 2006), judges lack the opportunity to develop experience through practice. Therefore, policy interventions are needed to create a greater awareness in the judiciary, not only to understand but also to interpret intellectual-property-related laws.

Our sensitivity analysis conducted for Stage 2 countries shows the important relationship between Judicial Independence and managers' business ethics perceptions (see Table 9). More specifically, the results indicate that JI has the greatest explanatory power over EBOF. This finding clearly points out the importance of ensuring the independence of courts/judges, which should be attained and protected through the highest authority of the law, such as through a country's constitution. Any legislative moves that may be perceived as weakening Judicial Independence may have detrimental macro-level ramifications.

When it comes to Stage 3 (innovation-driven/advanced) countries, we observe that the current level of EBOF is already high. Therefore, the model depicting the network of business ethics in these countries (Figure 8) may potentially serve as the benchmark for policy makers in Stage 1 and Stage 2 countries. As evident from Table 9, the Irregular Payments and Bribes variable has the greatest explanatory power on EBOF for Stage 3 countries. IPAB is the critical factor that Stage 1 and Stage 2 countries should address to attain a higher state of EBOF. Table 11 clearly demonstrates the strong relationship between perceptions of bribery activities and perceptions of business ethics.

Moreover, as the sensitivity analysis of the overall model suggests (Table 9), perceived bribery activities have the greatest explanatory power over managers' ethical behavior perceptions globally. Scholars in various disciplines, including public policy, international business, business ethics, marketing, management, and law have for decades tried to offer solutions to reduce bribery (Argandona 2007; Cleveland et al. 2010; Pacini, Swinger, and Rogers 2002; Williams and Beare 1999), but the problem persists and continues to create unfair competition among companies and nations. Considering the economic and social consequences of bribery and its relation to ethical perceptions (as stated in our findings), we recommend continuing to focus efforts on delineating the "system" of bribery.

\section{Other Macromarketing Implications}

Even though the focus of this paper is on firms' ethical behavior (and therefore, the EBOF variable), the models presented in this manuscript are also informative about the remaining nine variables. Economic development is one of the most important issues that macromarketing scholars have explored over the years (Layton 2009). Many factors may account for economic development, but the role that Intellectual Property Protection plays appears particularly important (Bruton 2004; 
Table I 2. Results of the Sensitivity Analysis for Cluster.

\begin{tabular}{lc}
\hline Indicator & Variance \\
\hline IPAB & 47.6 \\
IPP & 46 \\
EBOF & 44.8 \\
\hline
\end{tabular}

Table 13. Results of the Sensitivity Analysis for IPP.

\begin{tabular}{lcllc}
\hline Factor-Driven Stage I & & \multicolumn{2}{c}{ Efficiency-Driven Stage 2 } \\
\cline { 1 - 1 } Indicator & Variance Reduction (\%) & & Indicator & Variance Reduction (\%) \\
\hline EBOF & 33.7 & & EBOF & 28.9 \\
SOARS & 27.5 & SOARS & 28.3 \\
\hline
\end{tabular}

Carmen and Dominguez 2001; Chance and Deshpande 2009; Shultz 2012). Citing Helpman (2004), Layton (2009) noted that economic development "has its origin... in the accumulation of knowledge, and in particular, the incentives for knowledge creation" (p. 349). As part of economic development, IPP can create an incentive system for knowledge creation. Protection of intellectual property rights has implications at the micro level by affecting firms' performance and willingness to participate in economic activities (Nelson 1995), as well as at the macro level by supporting the region's or nation's long-term growth (Abrams and Lewis 1995; Barro 1996; Carmen and Domingues 2001). As noted earlier, IPP has the greatest explanatory power over EBOF in underdeveloped countries (Stage 1) and the second-greatest power in developing (Stage 2) countries. Our analysis also highlights an important link between IPP and a country's development stage (i.e. economic development by WEF standards), and therefore provides additional empirical support for the efforts of macromarketing scholars.

More specifically, our sensitivity analysis conducted on the Cluster variable indicates that Intellectual Property Protection is one of the key indicators that explains a country's economic development stage. Whether a country is classified as factor, efficiency, or innovation driven can be explained by IPP by about $48 \%$ (Table 12). Further sensitivity analysis conducted on the IPP variable suggests that in Stage 1 and Stage 2 countries (where IPP issues are particularly problematic), Strength of Auditing and Reporting Standards is particularly important in explaining managers' IPP perceptions. In both types of countries, such perceptions can be explained by SOARS by about 28\% (Table 13). This finding may offer important insights for policy makers attempting to improve IPP perceptions in Stage 1 and Stage 2 countries because such perceptions are strongly related to perceptions of the country's general ethical climate.

\section{Concluding Remarks}

Macromarketing scholars have emphasized the importance of systemic/network approaches to business activities (e.g.
Mittelstaedt, Kilbourne, and Mittelstaedt 2006), and at the same time, pointed out the lack of (and therefore the need for) appropriate tools for macromarketing analysis (Dixon 2002; Fisk 2006). The Bayesian network method we utilize in this study allows researchers to analyze a domain from a system perspective. As noted earlier, the BN method is considered one of the most powerful tools for observing system changes. The method can also deal with multiple variables at once, which can lead to efficient scenario analyses, critical for understanding how a system functions. This study, to the best of our knowledge, is the first application of the BN methodology to a macromarketing topic. We believe that the adoption of this methodology by other researchers is likely to contribute to the discipline by advancing the understanding of how certain systemic/network relationships and various domains of macromarketing work.

\section{Acknowledgements}

The authors would like to thank to Special Issue Editor Ben Wooliscroft, Editor-in-Chief Terrence Witkowski, and the three anonymous reviewers for their valuable feedback.

\section{Declaration of Conflicting Interests}

The author(s) declared no potential conflicts of interest with respect to the research, authorship, and/or publication of this article.

\section{Funding}

The author(s) received no financial support for the research, authorship, and/or publication of this article.

\section{Note}

1. The WinMine programme can be accessed at http://research.microsoft.com/en-us/um/people/dmax/WinMine/tooldoc.htm. The tutorial can be accessed at http://research.microsoft.com/en-us/um/ people/dmax/WinMine/Tutorial/Tutorial.html.

\section{Supplemental Material}

"The online [appendices/data supplements/etc] are available at http:// jmk.sagepub.com/supplemental”.

\section{References}

Abrams, Burton A. and Kenneth A. Lewis (1995), "Cultural and Institutional Determinants of Economic Growth: A Cross-Sectional Analysis," Public Choice, 83 (3/4), 273-89.

Achumba, Ifeyinwa, Djamel Azzi, Felix K. Opara, Sebastian Bersch, and Ifeanyi Ezebili (2012), "On Selecting the Optimal Bayesian Network Model Construction Approach," in Proceedings of the World Congress on Engineering, Sio Iong Ao, Len Gelman, David Hukins, Andrew Hunter, and Alexander Korsunsky, eds., Vol II. London: World Congress of Engineering, 690-95.

Ahn, Jea-Hyeon and Kazuo J. Ezawa (1997), “Decision Support for Real-Time Telemarketing Operations through Bayesian Network Learning," Decision Support Systems, 21 (1), 17-27.

Alderson, Wroe and Reavis Cox (1948), "Towards a Theory of Marketing," Journal of Marketing, 13 (2), 137-152. 
Alderson, Wroe and Paul E. Green (1964), Planning and Problem Solving in Marketing. Homewood, IL: Irwin.

Allenby, Greg M., Thomas S. Shively, Sha Yang, and Mark J. Garratt (2004), “A Choice Model for Packaged Goods: Dealing with Discrete Quantities and Quantity Discounts," Marketing Science, 23 (1), 95-108.

Anderson, Ronald D. and Gyula Vastag (2004), "Causal Modeling Alternatives in Operations Research: Overview and Application," European Journal of Operational Research, 156 (1), 92-109.

Anthony, Keith D. (2006), "Introduction to Causal Modeling, Bayesian Theory and Major Bayesian Modeling Tools for the Intelligence Analyst," in Technical Report USAF National Air and Space Intelligence Center (NASIC) (accessed May 30, 2014), [available at http://www.au.af.mil/au/awc/awcgate/nasic/introcausal-modeling.pdf].

Argandona, Antonio (2007), “The United Nations Convention against Corruption and its Impact on International Companies," Journal of Business Ethics, 74 (4), 481-96.

Barro, Robert J. (1996), “Democracy and Growth," Journal of Economic Growth, 1 (1), 1-27.

Barton, David N., Sakari Kuikka, Olli Varis, Laura Uusitalo, Hans J. Henriksen, Mark Borsuk, Afirca de la Hera, Raziyek Farmani, Sandra Johnson, and John D. Linnelly (2012), "Bayesian Networks in Environmental and Resource Management," Integrated Environmental Assessment and Management, 8 (3), 418-29.

Blodgett, Jeffrey G. and Ronald D. Anderson (2000), “A Bayesian Network Model of the Consumer Complaint Process," Journal of Service Research, 2 (4), 321-38.

Boondao, Roungrasamme (2008), "Crime Risk Factors Analysis," in Bayesian Networks: A Practical Guide to Applications Bayesian Networks, Olivier Pourret, Patrick Naim, and Bruce Marcot, eds. Chichester, UK: John Wiley and Sons, 73-85.

Bromley, J., N. A. Jackson, O. J. Clymer, A. M. Giacomello, and F. V. Jensen (2005), "The Use of Hugin to Develop Bayesian Networks as an Aid to Integrated Water Resource Planning," Environmental Modelling \& Software, 20 (2), 213-42.

Browne, Ciara, Therry Geiger, and Tania Gutknecht (2013), "The Executive Opinion Survey: The Voice of the Business Community" in The Global Competitiveness Report, 2012-2013. Davos, Switzerland: World Economic Forum, (accessed May 30, 2014), [available at http://www.weforum.org/pdf/GCR08/Chapter\%202.1.pdf].

Burns, Jane O. and Pamela Kiecker (1995), "Tax Practitioner Ethics: An Empirical Investigation of Organizational Consequences," Journal of the American Taxation Association, 17 (2), 20-49.

Bruton, Christopher F. (2004), "Critical Issues for Developing Asia," Journal of Macromarketing, 24 (2), 173-77.

Carmen, James M. and Luis V. Dominguez (2001), "Organizational Transformations in Transition Economies: Hypotheses," Journal of Macromarketing, 21 (2), 164-80.

Chance, Zoe and Rohit Desphande (2009), "Putting Patients First: Social Marketing Strategies for Treating HIV in Developing Nations," Journal of Macromarketing, 29 (3), 220-32.

Chickering, David M., Dan Geiger, and David Heckerman (1995), "Learning Bayesian Networks: Search Methods and Experimental Results," in Proceedings of the Fifth International Workshop on Artificial Intelligence and Statistics, 112-28, (accessed May 30,
2014), [available at http://research.microsoft.com/en-us/um/people/dmax/publications/aistats95.pdf].

Cinicioglu, Esma Nur, Prakash Shenoy, and Canan Kocabasoglu (2007), "Use of Radio Frequency Identification for Targeted Advertising: A Collaborative Filtering Approach Using Bayesian Networks," in Symbolic and Quantitative Approaches to Reasoning with Uncertainty, 9th European Conference, ECSQARU, Khaled Mellouli, ed. Berlin: Springer-Verlag, 889-900.

Cinicioglu, Esma Nur, Şule Önsel, and Füsun Ülengin (2012), “Competitiveness Analysis of Automotive Industry in Turkey Using Bayesian Networks," Expert Systems with Applications, 39 (12), 10923-32.

Clarke, Brenden, Bert Leuridan, and Jon Williamson (2013), "Modelling Mechanisms with Causal Cycles," Synthese, 191 (8), 1651-81.

Cleveland, Margot, Christopher M. Favo, Thomas J. Frecka, and Cherla L. Owens (2010), "Trends in the International Fight against Bribery and Corruption," Journal of Business Ethics, 90 (2), 199-244.

Dambacher, Jeffrey M., Will Shenton, Keith R. Hayes, Barry T. Hart, and Simon Barry (2007), "Qualitative Modelling and Bayesian Network Analysis for Risk-based Biosecurity Decision Making in Complex Systems," research report, Australian Centre of Excellence for Risk Analysis, The University of Melbourne.

Dixon, Donald (2002), "Emerging Macromarketing Concepts: From Socrates to Alfred Marshall," Journal of Business Research, 55 (February), 737-45.

Dogan, Ibrahim (2012), “Analysis of Facility Location Model Using Bayesian Networks," Expert Systems with Applications, 39 (1), 1092-104.

Donoho, Casey L., Michael J. Polonsky, J. Herche, and M. J. Swenson (1999), "A Cross Cultural Examination of the General Theory of Marketing Ethics: Does it Apply to the Next Generation of Marketing Managers?," in Proceedings of the Seventh Cross Cultural Research Conference, Scott Smith, ed. Provo, UT: Brigham Young University (CD-ROM, no page numbers).

Ekici, Ahmet and Sule Onsel (2013), "How Ethical Behavior of Firms is Influenced by theLegal and Political Environments: A Bayesian Causal Map Analysis Based on Stages of Development," Journal of Business Ethics, 115 (2), 271-90.

Fenton, Norman, Peter Hearty, Martin Neil, and Luhasz Radliński (2010), "Software Project and Quality Modelling Using Bayesian Networks," in Artificial Intelligence Applications for Improved Software Engineering Development: New Prospects," Farid Meziane and Sunni Vadera, eds. New York: Information Science Reference, 278-99.

Fisk, George (2006), "Envisioning the Future for Macromarketing," Journal of Macromarketing, 26 (2), 214-18.

Friedman, Nir, Michael Linial, Iftach Nachman, and Dana Peer (2000), "Using Bayesian Networks to Analyze Expression Data," Journal of Computational Biology, 7 (3/4), 601-20.

Fusco, Giovanni (2008), "Spatial Dynamics in the Coastal Region of South-Eastern France," in Bayesian Networks: A Practical Guide to Applications Bayesian Networks, Olivier Pourret, Patrick Naim, and Bruce Marcot, eds. Chichester, UK: John Wiley and Sons, 87-111.

Gran, Bjorn Axel (2002), “Assessment of Programmable Systems Using Bayesian Belief Nets,” Safety Science, 40 (9), 797-812. 
Green, Paul E. and Ronald E. Frank (1966), "Bayesian Statistics and Marketing Research," Journal of the Royal Statistical Society Series C (Applied Statistics), 15 (3), 173-90.

Gupta, Sumeet and Hee W. Kim (2008), “Linking Structural Equation Modeling to Bayesian Networks: Decision Support for Customer Retention in Virtual Communities," European Journal of Operational Research, 190 (3), 818-833.

Heckerman, David (1995), “A Tutorial on Learning with Bayesian Networks," technical report MSR-TR-95-06, Microsoft Research.

Heckerman, David, David M. Chickering, Christopher Meek, Robert Rounthwaite, and Carl Kadie (2000), "Dependency Networks for Inference, Collaborative Filtering, and Data Visualization," Journal of Machine Learning Research, 1 (Octobr), 49-75.

Helpman, Elharan (2004), The Mystery of Economic Growth. Cambridge, MA: Harvard University Press.

Hunt, Shelby D. and Arturo Vasquez-Parraga (1993), "Organizational Consequences, Marketing Ethics and Salesforce Supervision," Journal of Marketing Research, 30 (February), 78-90.

Hunt, Shelby D. and Scott M. Vitell (1986), "A General Theory of Marketing Ethics," Journal of Macromarketing, 6 (Spring), 5-15.

Hunt, Shelby D. and Scott M. Vitell (1993), "The General Theory of Marketing Ethics: A Retrospective and Revision," in Ethics in Marketing, N. Craig Smith and John A. Quelch, eds. Homewood, IL: Irwin, 775-84.

Ibarguengoytia, Pablo H., Enrique L. Sucar, and Sunil Vadera (2008), "Sensor Validation," in Bayesian Networks: A Practical Guide to Applications Bayesian Networks, Olivier Pourret, Patrick Naim, and Bruce Marcot, eds. Chichester, UK: John Wiley and Sons, 187-202.

Jensen, Kasper L., Jorn Toftum, and Peter Friis-Hansen (2009), “A Bayesian Network Approach to the Evaluation of Building Design and Its Consequences for Employee Performance and Operational Costs," Building and Environment, 44 (3), 456-62.

Kameri-Mtobe, Patricia (2008), Towards Greater Access to Justice in Environmental Disputes in Kenya: Opportunities for Intervention, International Environment Law Research Center, (accessed July 31, 2014), [available at http://www.ielrc.org/content/w0501.pdf].

Kim, Jeahwan, Greg M. Allenby, and Peter E. Rossi (2002), "Modeling Consumer Demand for Variety," Marketing Science, 21 (3), 229-50.

Korb, Kevin B. and Ann E. Nicholson (2011), Bayesian Artificial Intelligence. London: CRC Press.

Laczniak, Gene R. (1993), "Marketing Ethics: Onward Toward Greater Expectations," Journal of Public Policy and Marketing, 12 (1), 91-6.

Laczniak, Gene R. and Ann-Marie Kennedy (2011), "Hyper Norms: Searching for a Global Code of Conduct," Journal of Macromarketing, 31 (3), 245-56.

Lauria, Eitel J. M. and Peter J. Duchessi (2007), “A Methodology for Developing Bayesian Networks: An Application to Information Technology (IT) Implementation," European Journal of Operational Research, 179 (1), 234-52.

Layton, Roger A. (2009), “On Economics Growth, Marketing Systems, and the Quality of Life," Journal of Macromarketing, 29 (4), 349-62.

Layton, Roger A. and Sanfort Grossbart (2006), "Macromarketing: Past, Present, and Possible Future," Journal of Macromarketing, 26 (2), 193-213.
Lee, Eunchang, Yongtae Park, and Jong G. Shin (2009), "Large Engineering Project Risk Management Using a Bayesian Belief Network," Expert Systems with Applications, 36 (3), 5880-87.

Lin, Jau-Huei and Peter J. Haug (2008), “Exploiting Missing Clinical Data in Bayesian Network Modeling for Predicting Medical Problems," Journal of Biomed Inform, 41 (1), 1-14.

Mase, Shigeru (2008), "Credit-rating of Companies," in Bayesian Networks: A Practical Guide to Applications Bayesian Networks, Olivier Pourret, Patrick Naim, and Bruce Marco, eds. Chichester, UK: John Wiley and Sons, 33-52.

Mayo, Michael A. and Lawrance J. Marks (1990), “An Empirical Investigation of A General Theory of Marketing Ethics," Journal of the Academy of Marketing Science, 18 (Spring), 163-72.

Menguc, Bülent (1998), "Organizational Consequences, Marketing Ethics, and Salesforce Supervision: Further Empirical Evidence," Journal of Business Ethics, 17 (4), 333-52.

Mittelstaedt, John, William E. Kilbourne, and Robert A. Mittelstaedt (2006), "Macromarketing as Agorology: Macromarketing Theory and the Study of the Agora," Journal of Macromarketing, 26 (2), $131-42$.

Murphy, Patrick and Gene Laczniak (1981), "Marketing Ethics: A Review with Implications for Managers, Educators, and Researchers," in Review of Marketing, Ben M. Enis and Kenneth J. Roering, eds. Chicago, IL: American Marketing Association, 251-66.

Nadkarni, Sucheta and Prakash Shenoy (2004), “A Causal Mapping Approach toConstructing Bayesian Networks," Decision Support Systems, 38 (2), 259-81.

Nash, David, David Waters, Andres Buldu, Yuming Wu, Yaping Lin, Weiqiu, Yuzhi Yang Song, Jianhua Shu, Wei Qin, and Murray Hannah (2013), "Using a Conceptual Bayesian Network to Investigate Environmental Management of Vegetable Production in the Lake Taihu Region of China," Environmental Modelling \& Software, 46 (August), 170-81.

Nelson, Richard R. (1995), "Recent Evolutionary Theorizing about Economic Change," Journal of Economic Literature, 33 (March), 48-90.

Netica Software (2014), (accessed MAY 30, 2014), [available at http://www.norsys.com/dl/Netica_Win.exe].

Nicholson, Ann E., Charles R. Twardy, Kevin B. Korb, and Lucas R. Hope (2008), "Decision Support for Clinical Cardiovascular Risk Assessment," in Bayesian Networks: A Practical Guide to Applications Bayesian Networks, Olivier Pourret, Patrick Naim, and Bruce Marcot, eds. Chichester, UK: John Wiley and Sons, 33-52.

Niedermayer, Daryle (2008), “An Introduction to Bayesian Networks and Their Contemporary Applications" in Innovations in Bayesian Networks (Studies in Computational Intelligence), Dawn E. Holmes and Lakhmi C. Jain, eds. Berlin: L.C. Springer, 117-30.

Nill, Alexander and John A. Schibrowsky (2007), "Research on Marketing Ethics: A Systematic Review of Literature," Journal of Macromarketing, 27 (3), 256-73.

Onisko, Agnieszha (2008), "Medical Diagnosis," in Bayesian Networks: A Practical Guide to Applications Bayesian Networks, Olivier Pourret, Patrick Naim, and Bruce Marcot, eds. Chichester, UK: John Wiley and Sons, 15-32. 
Pacini, Carl, Judyth A. Swingen, and Hudson Rogers (2002), "The Role of the OECD and EU Conventions in Combating Bribery of Foreign Public Officials," Journal of Business Ethics, 37 (4), 385-405.

Pourret, Olivier (2008), "Introduction to Bayesian Networks," in Bayesian Networks: A Practical Guide to Applications Bayesian Networks, Olivier Pourret, Patrick Naim, and Bruce Marcot, eds. Chichester, UK: John Wiley and Sons, 1-13.

Sala-i Martin, Xavier, Benat Bilbao-Osorio, Jennifer Blanke, Roberto Crotti, Thierry Geiger, and Caroline Ko (2012), "The Global Competitiveness Index 2012-2013: Strengthening Recovery by Raising Productivity," (accessed on May 30, 2014), [available at http:// www3.weforum.org/docs/CSI/2012-13/GCR_Chapter1.1_201213.pdf].

Schlaifer, Robert (1959), Probability and Statistics for Business Decisions. New York: McGraw Hall.

Scuderi, Marco and Kelly Clifton (2005), "Bayesian Approaches to Learning from Data: Using NHTS Data for the Analysis of Land Use and Travel Behavior," Bureau of Transportation Statistics. Washington, DC: US Department of Transportation.

Sebastiani, Paola and Thomas Perls (2008), "Complex Genetic Models," in Bayesian Networks: A Practical Guide to Applications Bayesian Networks, Olivier Pourret, Patrick Naim, and Bruce Marcot, eds. Chichester, UK: John Wiley and Sons, 53-72.

Shultz, Clifford (2012), "Vietnam: Political, Economy, Marketing System," Journal of Macromarketing, 32 (1), 7-17.

Sikoyo, Goerge M., Elvin Nyukuri, and Judi W. Wakhungu (2006), "Intellectual Property Protection in Africa," (accessed on May 30, 2014), [available at http://dspace.africaportal.org/jspui/bit stream/123456789/34805/1/ecopolicy16\%20(1).pdf?1].

Singhapakdi, Anusorn and Scott J. Vitell (1990), "Marketing Ethics: Factors Influencing Perceptions of Ethical Problems and Alternatives," Journal of Macromarketing, 10 (Spring), 4-18.

Stamelos, Ioannis, Lefteris Angelis, Panagiotis Dimou, and E. Sakellaris (2003), "On the Use of Bayesian Belief Networks for the Prediction of Software Productivity," Information and Software Technology, 45 (1), 51-60.

Ulengin, Füsun, Sule Onsel, Emel Aktaş, Özgür Kabak, and Özay Özaydın (2014), “A Decision Support Methodology to Enhance the Competitiveness of the Turkish Automotive Industry," European Journal of Operational Research, 234 (3), 789-801.

Vitell, Scott J., Anusorn Singhapakdi, and James Thomas (2001), "Consumer Ethics: An Application and Empirical Testing of the Hunt-Vitell Theory of Ethics," Journal of Consumer Marketing, 18 (2), 153-78.

Weber, Philippe, Gabriela Medina-Oliva, Christophe Simon, and Benoit Iung (2012), "Overview on Bayesian Networks Applications for Dependability, Risk Analysis and Maintenance Areas," Engineering Applications of Artificial Intelligence, 25 (4), 671-82.

Williams, James W. and Marharet E. Beare (1999), “The Business of Bribery: Globalization, Economic Libarilization, and the Problem of Corruption," Crime, Law \& Social Change, 32 (2), 115-46.

World Economic Forum (WEF) (2012), The Global Competitiveness Report 2012-2013. Davos: Switzerland.

Yang, Sha and Greg M. Allenby (2003), "Modelling Interdependent Consumer Preferences," Journal of Marketing Research, 15 (August), 282-94.

\section{Author Biographies}

Ahmet Ekici (Ph.D., University of Nebraska-Lincoln) is an Associate Professor of Marketing at Bilkent University. His main research areas are public policy and marketing; macromarketing and relationship marketing. His refereed articles have been published in a variety of journals including Journal of Macromarketing, Journal of Business Ethics, Industrial Marketing Management, Journal of Business Research, Journal of Public Policy \& Marketing, and Social Indicators Research.

Sule Onsel Ekici ( $\mathrm{PhD}$, Istanbul Technical University) is an Associate Professor of Decision Making at Dogus University, Istanbul. Her research topics are scenario analysis, neural networks, cognitive mapping, and Bayesian networks. Her refereed articles have appeared in a variety of journals including Expert Systems with Applications, Transportation Research Part C, Socio Economic Planning Sciences, European Journal of Operational Research, and International Journal of Production Research. 